\title{
Reconstructing eruptive source parameters from tephra deposit: a numerical study of medium-sized explosive eruptions at Etna volcano
}

\author{
Antonio Spanu ${ }^{1,2,3}$ • Mattia de' Michieli Vitturi ${ }^{1} \cdot$ Sara Barsotti ${ }^{1,4}$
}

Received: 23 September 2015 / Accepted: 3 July 2016 / Published online: 10 August 2016

(C) The Author(s) 2016. This article is published with open access at Springerlink.com

\begin{abstract}
Since the 1970s, multiple reconstruction techniques have been proposed and are currently used, to extrapolate and quantify eruptive parameters from sampled tephra fall deposit datasets. Atmospheric transport and deposition processes strongly control the spatial distribution of tephra deposit; therefore, a large uncertainty affects mass derived estimations especially for fall layer that are not well exposed. This paper has two main aims: the first is to analyse the sensitivity to the deposit sampling strategy of reconstruction techniques. The second is to assess whether there are differences between the modelled values for emitted mass and grainsize, versus values estimated from the deposits. We find significant differences and propose a new correction strategy. A numerical approach is demonstrated by simulating with a dispersal code a mild explosive event occurring at Mt. Etna on 24 November 2006. Eruptive parameters are reconstructed by an inversion
\end{abstract}

Editorial responsibility: C. Bonadonna

Electronic supplementary material The online version of this article (doi:10.1007/s00445-016-1051-2) contains supplementary material, which is available to authorized users.

Antonio Spanu

antonio.spanu@univie.ac.at

1 Istituto Nazionale di Geofisica e Vulcanologia, Sezione di Pisa, Pisa, Italy

2 Scuola Normale Superiore di Pisa, Pisa, Italy

3 Now at University of Vienna Aerosol Physics and Environmental Physics, Boltzmanngasse 51090 Vienna, Austria

4 Now at Icelandic Meteorological Office, Reykjavík, Iceland using available tephra information collected after the eruption. A full synthetic deposit is created by integrating the deposited mass computed by the model over the computational domain (i.e., an area of $7.5 \times 10^{4} \mathrm{~km}^{2}$ ). A statistical analysis based on 2000 sampling tests of 50 sampling points shows a large variability, up to $50 \%$ for all the reconstruction techniques. Moreover, for some test examples Power Law errors are larger than estimated uncertainty. A similar analysis, on simulated grain-size classes, shows how spatial sampling limitations strongly reduce the utility of available information on the total grain size distribution. For example, information on particles coarser than $\phi(-4)$ is completely lost when sampling at $1.5 \mathrm{~km}$ from the vent for all columns with heights less than $2000 \mathrm{~m}$ above the vent. To correct for this effect an optimal sampling strategy and a new reconstruction method are presented. A sensitivity study shows that our method can be extended to a wide range of eruptive scenarios including those in which aggregation processes are important. The new correction method allows an estimate of the deficiency for each simulated class in calculated mass deposited, providing reliable estimation of uncertainties in the reconstructed total (whole deposit) grainsize distribution.

Keywords Tephra deposit - Eruptive source parameters . Dispersal model · Grain size distribution · TGSD · Erupted mass $\cdot$ Sampling strategy

\section{Introduction}

A primary objective in volcanology, critical for hazard assessment of active volcanoes, is the characterization of explosive volcanic eruptions and the quantification of their intensities. Accurately estimating eruptive source parameters 
(ESPs), such as mass eruption rate (MER), is necessary if we are to deepen our understanding of eruptive column and ash cloud dynamics. In addition, knowledge of the total (whole deposit) grain size distribution (TGSD) of the solid particles at the vent is needed if we are to better understand the mechanisms occurring within the conduit during an eruption. This is commonly viewed as comprising a primary fragmentation of magma during rapid decompression producing large fragments (Alidibirov and Dingwell 1996) and a secondary one producing fine ash (Kaminski and Jaupart 1998). These processes will result in solid particles of various sizes, ranging from meters to a few microns, with those of several centimeter and smaller (tephra) carried into the atmosphere and subsequently settled toward the ground under the action of atmospheric dynamics, aggregative processes, and gravity. Atmospheric transport processes, controlled by particle characteristics (size, density, and shape) and altitude of release from the column (depending on MER and atmospheric conditions), affect aerial distribution over timescales ranging from a few hours up to weeks. The area affected by ash fallout can extend over thousands of square kilometers around the vent (Sparks et al. 1997). Recently, Bursik et al. (2012), Degruyter and Bonadonna (2013), Woodhouse et al. (2013) and Mastin (2014) investigated wind effects on column dynamics and height, revealing the importance of taking wind into account in order to avoid strong under-estimation of mass flow-rates. For all the aforementioned reasons, uncertainty associated with the tephra dispersal process is quite large and an accurate estimation of total erupted mass and TGSD is a complex and still daunting task.

During a volcanic crisis, several direct measurements are a useful source of information about the ongoing activity. Remote sensing instruments provide estimates of column (Rose et al. 1995; Arason et al. 2011) and plume height (Vernier et al. 2013; Grainger et al. 2013), duration of the event (Johnson et al. 2004), gas and particle exit velocities (Dubosclard et al. 2004), and plume composition (Rose et al. 2000; Spinetti et al. 2013). However, satellite retrievals provide only column-integrated information and are strongly sensitive to the presence of atmospheric clouds above the ash plumes and to assumptions about ash size distribution and ash composition (Wen and Rose 1994). Moreover, most of the band spectra used by remote sensing instruments are not very sensitive to the presence of particles larger than 32 microns, and consequently, they detect only a fraction of the erupted mass. Corradini et al. (2008) estimate satellite retrieved total mass uncertainty to be on the order of $40 \%$ increasing up to $50 \%$ when considering non-spherical particles (Kylling et al. 2014). For sun photometers coupled with Lidar measurements (Gasteiger et al. 2011 ) estimated a $50 \%$ error in mass concentrations. Due to these limitations, the deposit is still one of the main products that must be analyzed in order to estimate the cumulative erupted mass (EM) and total grain-size distribution (TGSD) of an eruption.

Historically, the volume of solid erupted material has been estimated from discrete samplings of deposit thickness (Fisher 1964; Walker 1973). In recent decades, several techniques have been proposed to optimize the integration of field data and to obtain an estimate of the emitted material (Pyle 1989; Fierstein and Nathenson 1992). Bonadonna and Houghton (2005) and Bonadonna and Costa (2012) introduced other methods, commonly adopted by volcanologists during their field studies, for estimating volume and total grain size distribution. More, recently, Burden et al. (2013) and Engwell et al. (2013) used statistical methods to study the uncertainty in volume estimation (estimated to be between 1 and $10 \%$ for small datasets), associated with uncertainties in tephra thickness measurements. Additional studies addressing estimation of uncertainty for erupted mass, based solely on field data, can be found in Andronico et al. (2014a), Klawonn et al. (2014b), Engwell et al. (2015), and Bonadonna et al. (2015).

In the past decade, several attempts have been made to integrate field data analysis with other approaches in order to better constrain the initial eruptive conditions. Gudmundsson et al. (2012) integrated ground measurements with satellite observations. Recently, Stevenson et al. (2015) integrated tephrochronology, dispersion modeling and satellite remote sensing to understand the discrepancy between tephra deposit and satellite infrared measurements.

The importance of accurately estimating eruptive source parameters (ESPs) is in part due to the growing use of dispersal codes for ash hazards assessment (Sparks et al. 1997; Textor et al. 2005; Folch 2012; Fagents et al. 2013). The reliability of the output from such tephra dispersal models depends strongly on the reliability and uncertainty of ESPs. In recent years, the application of inversion techniques to tephra dispersal models, based on advection-diffusion sedimentation equations, has shown promise for determining EPSs (Connor and Connor 2006; Burden et al. 2011; Bursik et al. 2012; Pardini et al. 2016; Scollo et al. 2008; Bonasia et al. 2010; Volentik et al. 2010; Fontijn et al. 2011; Johnston et al. 2012; Klawonn et al. 2012; Magill et al. 2015).

In this paper, we use a modeling approach to assess the representativeness of information contained in a tephra ground deposit. We pursue this objective by simulating an eruptive event at Mt. Etna for which we first calculated ESPs via an inversion of field-measurements of deposit mass. Then, we numerically compute deposited masses for each grain size (DMi) and compare them with the modeled corresponding masses emitted at the vent (EMi). In this way, we quantify, as a function of column height and domain size, the amount of erupted mass that was not deposited in the considered domain. Furthermore, to test the efficacy 
of reconstruction techniques in quantifying ESPs, we randomly sample the modeled deposit and then estimate the deposited mass for the each of grain size (DMi*). We repeat this process multiple times, in order to perform a statistical analysis on the results of the different techniques and to assess their uncertainty, as schematically illustrated in Fig. 1. Finally, based on the results from a large number of simulations for different ESPs, we propose, as a function of grain size, column height and extension of sampling domains, some correction factors to fill the gap between modeled emitted eruptive parameters and value estimated from the modelled deposit.

\section{Methods}

\section{Numerical model}

We use the dispersal code VOL-CALPUFF (Barsotti et al. 2008) to simulate the transport of volcanic ash cloud in a transient and 3D atmosphere and to compute a synthetic deposit. No other models have been tested here since the purpose of this study is analysing the sensitivity and uncertainty of reconstruction techniques instead of testing different models (for a review of dispersal model see Folch (2012)). VOL-CALPUFF couples an Eulerian description of the initial plume rise phase, where plume theory equations are solved (Morton 1959; Bursik 2001), with a Lagrangian description of the transport of material leaving the eruptive column. The model calculates mass lost along the column for each class size as a function of settling velocities. Settling velocity is computed as a function of particle Reynolds number and depends on particle characteristics (dimension, density, shape) as well as atmospheric properties (air density and viscosity), according with the modification of the Wilson and Huang (1979) model, as presented in Pfeiffer et al. (2005). Particles of different sizes are released from the column as a series of Gaussian packets (puffs), which are transported and diffused by the wind during their fall toward the ground due to gravity. Tracking puff movements within the 3D domain, the code computes at each time step the amount of mass advected out of the domain, still suspended in the atmosphere and deposited on the ground. VOL-CALPUFF has been tested and adopted to simulate volcanic ash dispersal and deposition at several volcanoes worldwide (Barsotti and Neri 2008; Barsotti et al. 2011; Spinetti et al. 2013; Barsotti et al. 2015).

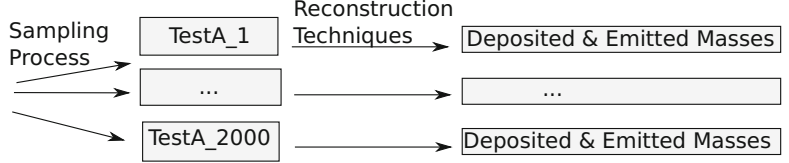

For the application presented in this paper, we initialized VOL-CALPUFF with meteorological input data produced by the non-hydrostatic code LAMI (Doms and Schättler 2002) with $7 \mathrm{~km}$ horizontal resolution and 23 vertical levels and refined down to one km horizontally and one hour in time by the processor CALMET (Scire et al. 2000).

\section{Inversion modelling and best-fitting criterion}

Optimal values of ESPs (e.g. mass eruption rate, TGSD) are inferred by using an inversion method where we compare simulated mass ground loading data (hereafter refer as loading) with field measurements. The best set of parameters used to define the eruptive scenario is obtained by minimizing the following error:

$$
\begin{aligned}
\left\|e r r_{\text {tot }}\right\|= & \left\|\operatorname{err}_{\text {Loading }}\right\|+\left\|\operatorname{err}_{T G S D}\right\| \\
= & \left\|\sum_{i}^{N_{\text {sampled }}} \frac{(\log (M(i))-\log (\overline{M(i)}))}{N_{\text {sampled }}}\right\| \\
& +\left\|\sum_{i}^{N_{\text {sieved }}} \sum_{j}^{N_{\text {classe }}} \frac{\left(M_{j}(i)-\overline{M_{j}(i)}\right)}{\left(N_{\text {sieved }} \cdot N_{\text {classes }}\right)}\right\|
\end{aligned}
$$

where $M(i)$ is the loading value measured on the collected location $i, \overline{M(i)}$ is the simulated value, and $M_{j}(i)$ is the loading for the $\mathrm{j}$-th class size. $N_{\text {classes }}$ is the number of classes in which the TGSD is partitioned. $N_{\text {sampled }}$ and $N_{\text {sieved }}$ are respectively the number of available measurements for total loading and for the sieved one. To invert the tephra loading, we use an iterative method. We first generate 4000 scenarios by varying the initial conditions (exit velocity, vent radius, and TGSD) and then we calculate the deposit for each hour. We kept the emission duration constant assuming the TGSD not varying during the event. Afterward, we calculate the errors for the simulated scenarios as expressed in Eq. 1. ESP values are then updated iteratively using a linear minimization method until we found a minimum for the error.

\section{Reconstruction techniques}

\section{Tephra deposit isopach}

The determination of the amount of erupted material is historically done starting from field measurements collected over the domain at discrete points (Walker 1973; Pyle 1989; Fierstein and Nathenson 1992). These data can be either

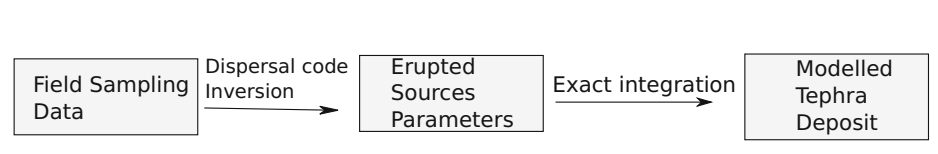

Fig. 1 Schematic representation of the computational strategy adopted 
measurement of deposit thickness for historical eruptions or of loading for more recent ones. Deposit information is generally completed by interpolating the point-wise measurements and by hand drawing isopachs. Klawonn et al. (2014b) analyzed the variability in handmade isopach, estimating a range of $\pm 10 \%$ for the associated uncertainty. Bursik and Sieh (2013) and Engwell et al. (2015) used a mathematical fitting function based on cubic splines in order to reduce the subjectivity in the process. Recently, Kawabata et al. (2015) proposed a different statistical method, based on fitting multiple ellipsoids. Here, to produce isopach maps in an objective and automatic way, we adopt the Natural Neighbor (NN) interpolation method introduced by Sibson (1981). The Natural Neighbor method is an exact interpolation technique based on Voronoi tessellation of a discrete set of spatial points. The method has been already applied to geophysical problems and performs well for irregularly distributed data (Watson and Phillip 1987; Sambridge et al. 1995). Moreover, NN provides a smooth approximation by a weighted average within the sample set of the interpolation point's neighbor values. We used a NN algorithm distributed with the NCAR Graphics Library (Brown et al. 2012a).

\section{Erupted mass}

In the past, different methods have been proposed to estimate erupted volume from deposit data (Rose et al. 1973; Pyle 1989; Fierstein and Nathenson 1992; Sulpizio 2005; Bonadonna and Costa 2012), where the estimation process consists of several common steps. The first step is to draw a discrete number $(\mathrm{N})$ of isopach (or isomass) contours, as described above. The second step is to express the thickness $t_{i}$ as a function of its corresponding isopach area square-root $x_{i}$. This is done with a curve-fitting procedure, where the function $t(x)$ is chosen from a fixed family, described by one or more parameter, by minimizing a residual function. Finally, the erupted volume is calculated by integrating the selected function. Recently, Burden et al. (2013) proposed an alternative method avoiding drawing isomass maps and using a statistical method on the sampling point measurements.
Within the first category of methods, in our work, we test the following families of fitting functions (see also Table 1):

1) Exponential or Pyle's method (Pyle 1989). This method assumes that thickness, calculated on circular isopachs, follows an exponential decay with distance from the vent. Fierstein and Nathenson (1992) and Bonadonna and Houghton (2005) generalized the method for elliptical isopachs and for accounting the break-in-slope of some tephra deposits, by using various exponential segments. This method is now widely used even though it is very sensitive to the number of straight segments and their extremes. In order to reduce the arbitrariness of the process (in particular in the choice of the segments extremes), we define an automatic procedure, where we select also the break-in-slope points within the minimization process involving the fitting.

2) Power-law method (Bonadonna and Houghton 2005). In their paper, the authors suggest a power-law best fit of field data to obtain the total erupted volume. This volume can be calculated as $V=\int 2 t_{p l} x^{m+1} d x$, where $t_{p l}$ is the thickness associated to the unit area isomass. Unfortunately, this integral, when evaluated over the interval $[0,+\infty]$, is infinite. To avoid this problem such an interval is replaced by a smaller one $\left[x_{0}, x_{1}\right]$, where $x_{0}$ and $x_{1}$ represent respectively, the exclusion of the proximal area and the distal region from the domain. As already stated by Bonadonna and Costa (2013), this choice depends on the power-law exponent and strongly influences Power-law results . For this reason, in our statistical analysis, average values of these distances are fixed at 1 and $300 \mathrm{~km}$ (accordingly with the eruption size) with a range of variability equal to $\pm 10 \%$.

3) Weibull method (Bonadonna and Costa 2012; 2013). The method is based on the assumption that the function $x T(x)$ can be described by a Weibull distribution with three main parameters $(\lambda, \theta, n)$. $\lambda$ represents the characteristic decay length scale of deposit thinning, $\theta$ represents a thickness scale and $n$ is a shape parameter (dimensionless).
Table 1 Reconstruction methods presented with explicit formulas for loading $(t)$ as a function of corresponding isomass squareroot areas (x), and residual cost functions

\begin{tabular}{llll}
\hline Method & Formula t(x) & Residual function & Free parameters \\
\hline Exponential & $t_{0} \exp (m x)$ & $\sum_{i=1, N}\left(\log (t(x i))-\log \left(t_{i}\right)\right)^{2}$ & 6 \\
Power-law & $t_{p} x_{m}$ & $\sum_{i=1, N}\left(\log (t(x i))-\log \left(t_{i}\right)\right)^{2}$ & $2+2$ arb \\
Weibull 1 & $\theta(x / \lambda)^{n-2} \exp \left(-(x / \lambda)^{n}\right)$ & $\sum_{i=1, N}\left(t\left(x_{i}\right)-t_{i}\right)^{2}$ & 3 \\
Weibull 2 & $\theta(x / \lambda)^{n-2} \exp \left(-(x / \lambda)^{n}\right)$ & $\sum_{i=1, N} 1 / t_{i}^{2}\left(t\left(x_{i}\right)-t_{i}\right)^{2}$ & 3 \\
Weibull 3 & $\theta(x / \lambda)^{n-2} \exp \left(-(x / \lambda)^{n}\right)$ & $\sum_{i=1, N} 1 / t_{i}\left(t\left(x_{i}\right)-t_{i}\right)^{2}$ & 3 \\
\hline
\end{tabular}

$\mathrm{N}$ is the number of isomass. For Weibull methods (referring to Weibull 1, 2, and 3), parameters have been chosen, according to Bonadonna and Costa (2012), in the best initial range $\lambda \in[0.1,1000] \mathrm{km}$, $\theta \in[0.1,5000] \mathrm{cm}$ and $n \in[0.2,2]$ 
In this work, model outcomes are expressed as loadings, so we apply all previous methods for the mass estimation by considering isomass contours instead of isopachs as frequently done in case of fresh deposit (Scollo et al. 2007; Andronico et al. 2008; Andronico et al. 2009).

\section{Grain-size distribution}

Total grain-size distribution (TGSD) of tephra-fall deposits is a crucial ESP for tephra-dispersal modelling and risk mitigation plans (Scollo et al. 2008; Folch 2012) and several techniques have been developed to reconstruct it starting from ground information, e.g., Murrow et al. (1980) and Bonadonna and Houghton (2005). Usually, grain size is expressed in $\phi$ scale where $\phi=-\log _{2}\left(\mathrm{~d} / \mathrm{d}_{0}\right), \mathrm{d}$ is the particle diameter, and $\mathrm{d}_{0}$ is a reference diameter of $1 \mathrm{~mm}$. For reconstructing the TGSD different techniques exist: weighted average, sectorization of the deposit, or isomass maps of individual $\phi$ classes. Nevertheless, the Voronoi method adopted in Bonadonna and Houghton (2005) for the TGSD reconstruction is widely used by the volcanological community. For this reason, we chose it in our work for a comparison with the emitted and deposited TGSD. Voronoi, or nearest-neighbor, technique is a constant piecewise interpolation method built upon the Voronoi tessellation (Voronoi 1907). Given a set of points called seeds, the plane, over which they lay, is partitioned into convex cells, each one consisting of all those points closer to that seed than to any others.

Then, as proposed in Bonadonna and Houghton (2005), the grain size and loading of each sample point are assigned to the corresponding Voronoi cell and the TGSD is obtained with a mass-weighted (where the mass is defined as the product between the cell area and the cell loading) average of all the sampled values over the whole deposit. The main requirement to apply the Voronoi method is to fix the deposit extent, adding deposit zero values to the original dataset. This step is essential to prevent the external Voronoi cells from having unlimited area and thus infinite mass. Dependence of the reconstructed TGSD on the location of the zeros has been previously recognized and discussed in Bonadonna and Houghton (2005), Bonadonna et al. (2015), and Volentik et al. (2010).

\section{Application to 24 November 2006 eruption at Mt. Etna}

Mt. Etna is the most active volcano in Europe, and each year it shows a wide variability in its eruptive activity. It has been extensively studied, and a wide literature exists regarding past activities, eruptive styles and products (Branca and Del Carlo 2005; Andronico et al. 2005; Scollo et al. 2007;
Andronico et al. 2008; Andronico et al. 2009; Andronico et al. 2014b). It is definitely an open-pit laboratory of volcanology and for all these reasons we have chosen it as our test case. In this paper, VOL-CALPUFF is used to simulate an eruption occurred on 24 November 2006, during which a 9-h-long eruption was observed with a column height estimated between 2000 and $2500 \mathrm{~m}$ above the ground level (agl) (Andronico et al. 2009). At that time a quite persistent wind was blowing toward south-east with intensities up to $10 \mathrm{~m} / \mathrm{s}$ at $3 \mathrm{~km}$ above the vent. Due to these meteorological conditions, the investigated domain, here fixed to $272 \times 277 \mathrm{~km}^{2}$, is displaced south-east of the vent.

A sensitivity analysis of column height as function of Mass Eruption Rate (MER) has been carried out assuming a bi-modal TGSD, obtained with a linear combination of two log-normal distributions with parameters $\mu_{1,2}$ and $\sigma_{1,2}$ respectively ranging in the intervals $[-3,5]$ and $[0.5,6]$. The initial distribution has been then partitioned in 23 classes equally spaced in the $\phi$ interval $[-5,6]$. Particles are assumed non spherical with a shape-factor of 0.43 within the range presented in Andronico et al. (2014b). Density is assumed varying with particles size according to Eychenne and Le Pennec (2012). Exit velocity and radius have been varied hourly.

Figure 2 presents the results of this sensitivity analysis. Different colors represent simulations with different emission time, thus subject to different atmospheric conditions. For a fixed column height, the variability in the wind field results in an uncertainty on estimated MER, across the 9-h time span investigated. For example, for a column height of $2000 \pm 100 \mathrm{~m} \mathrm{agl}$ (red box), the corresponding range of MER is $[1.5,4.5] \cdot 10^{4} \mathrm{~kg} / \mathrm{s}$. The main factors controlling this relationship are indeed the atmospheric environment, mainly wind speed, as already stated by Woodhouse et al. (2013), and temperature. The effect of different TGSDs on column height is minimum and it is estimated to be smaller than $10 \%$ by performing additional runs initialized modifying only the TGSD (see also de' Michieli Vitturi et al. 2015). For the same event, (Andronico et al. 2014b) calculated a MER of $4.82 \times 10^{3} \mathrm{~kg} / \mathrm{s}$ as coming from the estimated deposit, explaining this unusual value with an eruptive column rich in gas. A sensitivity study reveals that for a fixed column height the MER variation is inversely proportional to an augment on weight percent of water vapor $\left(x^{-1.04}\right)$.

\section{Inversion result: simulated scenario}

We apply the inversion procedure ("Inversion modelling and best-fitting criterion") to the Andronico et al. (2014b) dataset, composed by 27 total loading measurements among which 16 are sieved to obtain single loading. The resulting best Scenario has an average eruption column of $2000 \mathrm{~m} \mathrm{agl}$ 
Fig. 2 Column height

expressed as a function of Mass Eruption Rate. Different colors represent simulations with different starting times. Each circle represents a run with specific values for exit velocity, radius and a bi-modal grain size distribution. Circles size is function of velocity exit at the vent. The red box highlights the MER range corresponding to a column of $2000 \pm 100 \mathrm{~m}$ agl height

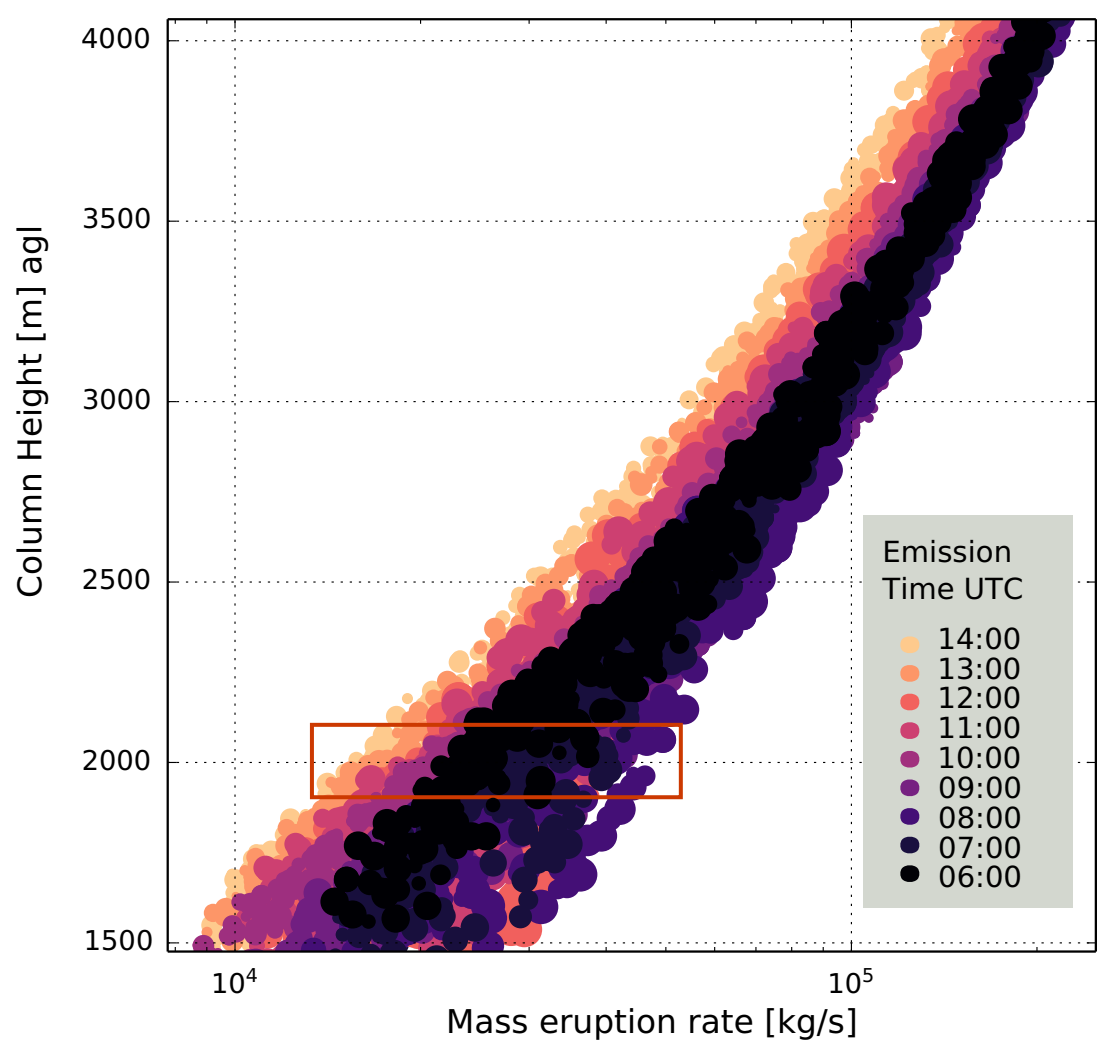

height and a total erupted mass of $7.7 \times 10^{8} \mathrm{~kg}$, corresponding to an average MER of $2.48 \times 10^{4} \mathrm{~kg} / \mathrm{s}$. Observations and calculated loading obtained with the inversion are compared in Fig. 3. The simulated Scenario reproduces reasonably well the observations on all the locations. Most of the points (78 \%) lie inside a factor two confidence interval from observations (gray dashed lines). In Fig. 3b, single loading comparison results in larger error, but it is still acceptable for most of the locations. Differences between observations and measurement can be attributed to many causes. In a dispersal model, errors are primary due to discrepancy in the simulated wind field or in the source description. Furthermore, simulations and measurements can differ due to time incongruence in the comparison. In our case, we calculated the deposit $24 \mathrm{~h}$ after the beginning of the eruption, while for the samples from Andronico et al. (2014a) the collection time is unknown. In Fig. 3c, the obtained TGSD is expressed on wt $\%$ as a function of the diameter in the $\phi$ scale. In red, we plot the assumed particles density according to Eychenne and Le Pennec (2012).

\section{Computed deposit}

Using the optimal ESPs resulting from the inversions, we simulated a dispersal Scenario. The dispersal model produces a numerical result on $250 \times 255$ computational cells.
At each cell center, we associate a loading value (mass per unit area), obtained from mass integration of Gaussian packets deposited on the ground over the cell. Hereafter, we will refer to this integration of Gaussian functions with the term "exact integration". Indeed, this is equivalent of using an infinite number of sampling points and consequently, approximation errors are close to zero. In this way, we calculate, for each simulated particle size, the cumulative amount of mass deposited over the computational domain. We remark that our approach, using as deposit the result of a numerical simulation, does not account for the effects of the natural variability in thickness values observed at small spatial scales in real deposits, but accounts only for the uncertainty associated with the reconstruction techniques. To this aim, in Kawabata et al. (2013), it is suggested to introduce a coefficient of variation between 0.2 (very complex model) and 0.5 (simple model) when modeling thickness variability in tephra deposition.

Figure 4a shows the simulated tephra deposit calculated $24 \mathrm{~h}$ after the eruption beginning. A considerable part of the deposit interests the inland (96\%) while a small amount falls into the sea. Deposit cross-wind extension mainly depends on wind temporal stability and direction during the eruptive event. Due to wind variability in direction with altitude and with time, the simulated eruption produces a wide deposit, which enlarges downwind the vent (Fig. 4a). 

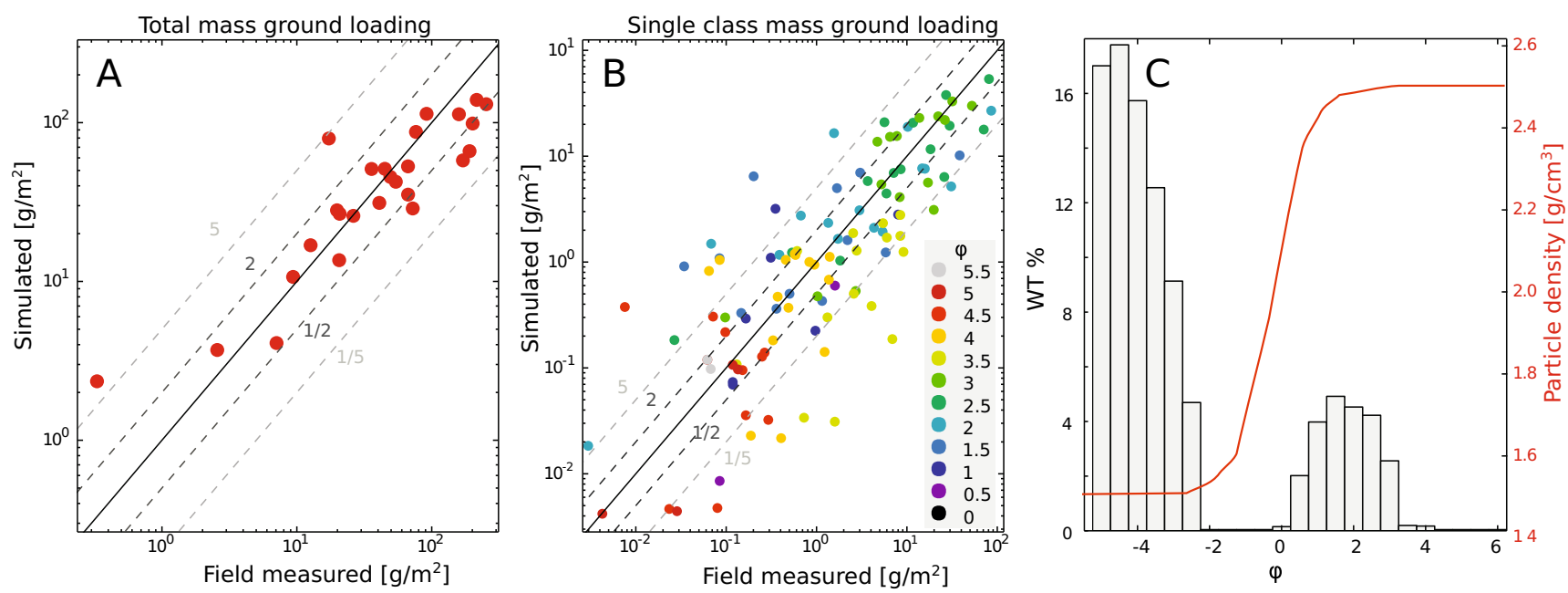

Fig. 3 Ground loadings for the eruptive Scenario obtained with the inversion procedure are compared with measurements obtained from the sampling locations reported in Andronico et al. (2014b): a total loading and $\mathbf{b}$ loading for single class divided on half- $\phi$ scale colored

\section{Sampling methodology}

Here, we test the stability of the reconstruction techniques presented in "Methods" by applying the methods to different sampling datasets. The whole set of $250 \times 255$ integral loading values is sampled to create 2000 smaller datasets ("sampling tests") of 50 points. For each sampling test, points are generated using a cylindrical coordinate system and the sampling procedure is performed using a uniform probability distribution along the major dispersal axis and a normal distribution for the angular coordinate. We calculate the major dispersal axis using simulated airborne concentrations and wind direction. Due to wind direction variability during the eruptive event, and therefore to the difficulty to find a major dispersal axis, a small random variability is considered in the angle for each sampling test. as a function of mean diameter. Dashed gray and light-gray lines correspond to $5(1 / 5)$ and $2(1 / 2)$ factors respectively. c Emitted TGSD expressed in $\mathrm{wt} \%$ in $\phi$ scale. In red, the corresponding sigmoidal particle density used according to Eychenne and Le Pennec (2012)

Tephra deposit sampling is often incomplete due to difficulties in sampling the very proximal or very distal regions. To reproduce this limitation, we exclude the area close to the vent from the sampling, but we include at least one point within $2 \mathrm{~km}$ from the vent in each test. We also sampled only inside the $10^{-2} \mathrm{~kg} / \mathrm{m}^{2}$ isomass contour (corresponding to $0.01 \mathrm{~mm}$, assuming a constant deposit density of $1000 \mathrm{~kg} / \mathrm{m}^{3}$ (Andronico et al. 2014b)) represented by black points. This value is chosen as a threshold in agreement with studies on eruptions of similar size (Andronico et al. 2008; Bonadonna and Houghton 2005; Scollo et al. 2007) and objective limitations on measurements for historical deposits. In order to keep the analysis more general, we have included in our dataset also points collected over the sea. Figure $4 \mathrm{~b}$ and $\mathrm{c}$ show two examples of sampling tests, respectively, TestA_1 and TestA_2, where the deposit
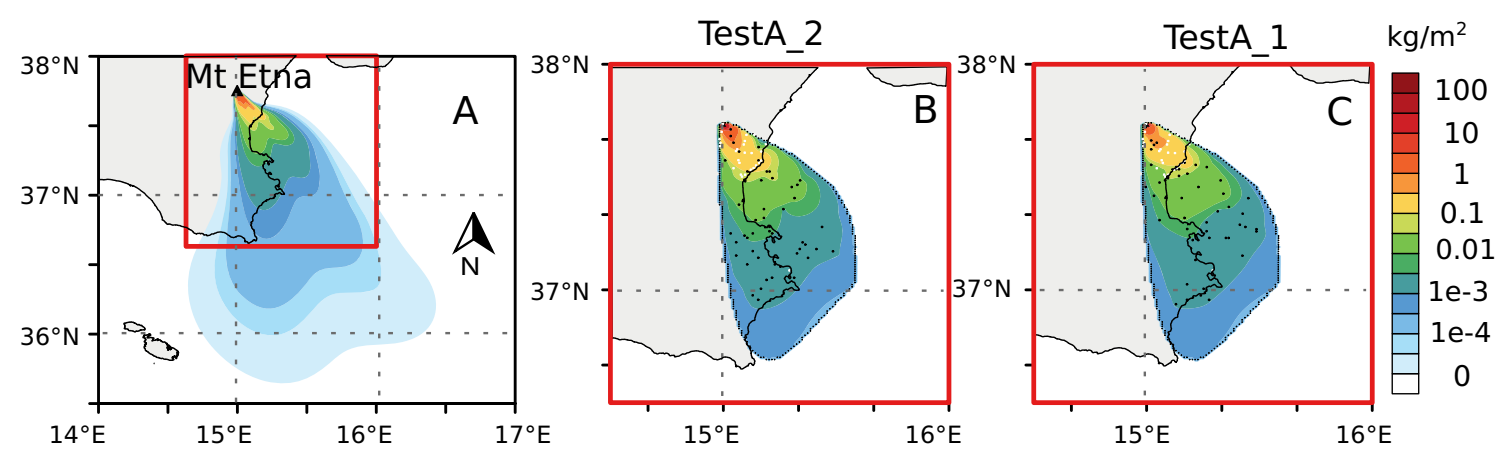

Fig. 4 a Computed loading contours for the synthetic deposit at the end of the simulation. The black triangle indicates the position of the eruptive vent. Isomass contours are log-spaced from $10^{-5}$ to $10^{2}\left[\mathrm{~kg} / \mathrm{m}^{2}\right]$. b, c Examples of sampling tests (black dots) with the corresponding reconstructed isomasses using NN. Small dark points outlining the contoured area represent imposed zero mass values. White dots are the sampling locations reported in Andronico et al. (2014b) 
mass is reconstructed using the Natural Neighbor (NN) interpolation method.

\section{Results}

In this section, mass and TGSD values, calculated using the "exact integration" (see "Erupted and deposited mass") and classical reconstruction techniques are compared with the known values used as Scenario input.

\section{Erupted and deposited mass}

Here, as already stated, we first perform an "exact integration" of the loading produced by the numerical simulation in each cell of the computational domain. Avoiding intermediate steps as interpolation techniques and fitting functions, we reduce all the subjective choices. In this way, the simulated deposit is analyzed to quantify the exact amount of emitted material falling in the considered domain of $7.4 \times 10^{4} \mathrm{~km}^{2}$ after $24 \mathrm{~h}$. In Fig. 5, cumulative mass and cumulative area vs. loading are plotted (dots). The total emitted mass is equal to $7.7 \times 10^{8} \mathrm{~kg}$ and the $99.83 \%$ of it is deposited over the domain.

With gray dashed lines, we refer to the 10, 50, and $90 \%$ of the total deposited mass and the corresponding loading which is, respectively, of 300,90 , and $0.8 \mathrm{~kg} / \mathrm{m}^{2}$. This reveals how the domain size and the considered thickness threshold influence the deposited mass. More than $90 \%$ of the emitted mass is deposited within an area of $3600 \mathrm{~km}^{2}$, and $10 \%$ lies in an area smaller than $1.3 \mathrm{~km}^{2}$.

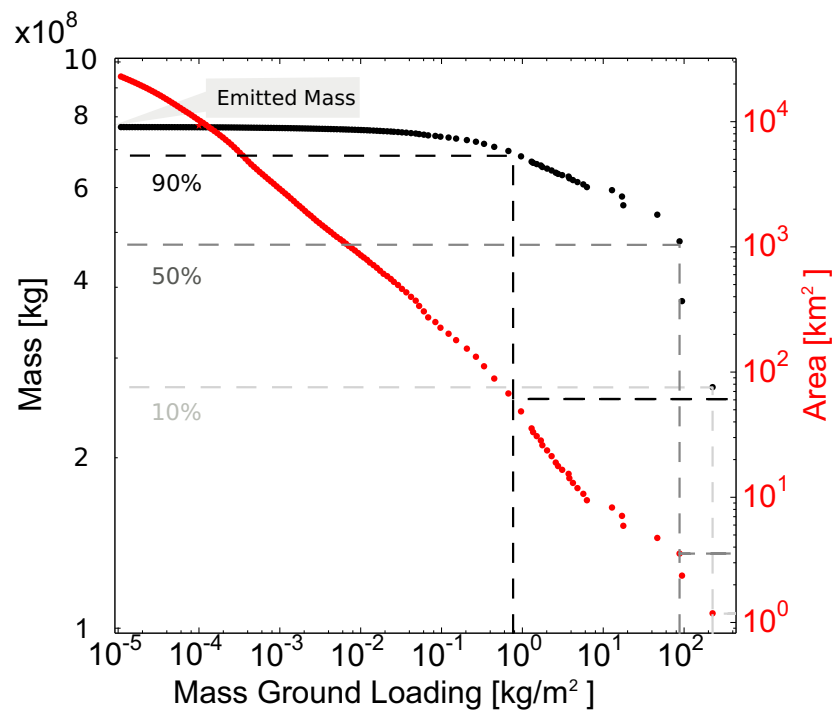

Fig. 5 Cumulative mass versus loading. The dashed lines denote the 10,50 , and $90 \%$ of the total deposited mass and the corresponding loading. In red, the isomass area is expressed as a function of its corresponding loading

\section{Comparison with reconstruction techniques}

In this section, we test all the previously introduced reconstruction techniques (Exponential, Power-law, and Weibull) using the different sampling tests.

First, for each of the 2000 tests, we apply the NN interpolation to the 50 sampled points and we extract 30 isomass contours from the reconstructed deposit. Statistical analysis results are plotted in Fig. 6a where we compare, for each isomass, the loading vs. square root area. The dashed line is calculated using the exact integration whereas the dark gray line represents the results median. The gray and light gray regions are respectively the $25^{\text {th }}-75^{\text {th }}$ and the $5^{\text {th }}-95^{\text {th }}$ percentiles. On average, for loadings larger than $5 \mathrm{~kg} / \mathrm{m}^{2}$ (which is where most of the deposited mass is concentrated, see Fig. 5), reconstructed isomass area values (Fig. 6a) are underestimated. On the contrary, for loading values smaller than $10^{-2} \mathrm{~kg} / \mathrm{m}^{2}$, areas are overestimated. This is mostly due to the spatial distribution of the sampling points, uniformly spaced along the dispersal axis. In Fig. $6 \mathrm{~b}$ and c, we plot, for the two examples presented in Fig. $4 \mathrm{~b}$ and c, the loading vs. square root area respectively with green and yellow dots. Using the different functions presented in Table 1, we fit these dots and best fitting functions are shown with solid lines. The black dashed line represents values obtained with the exact integration over the whole domain, as done for the plots in Fig. 5. In Fig. 6d, the estimated total mass is presented in a synthetic way, showing for each of the techniques the average values (averaged over the 2000 tests) with the $5^{\text {th }}$ and $95^{\text {th }}$ percentiles and the standard deviations. For an immediate comparison, the black line represents the erupted mass. On average, Exponential and Power Law are reconstructing well the emitted mass with an error smaller than $10 \%$. Weibull1 (weight $=1 / T_{i}$ ) and Weibull3 (weight=1) behave similarly with underestimations of $25 \%$. Weibull 2 (weight $=1 / T_{i}^{2}$ ), on average, overestimates the total mass up to one order of magnitude. In addition, we also present results from a Numerical Integration (Num-Int) where we integrate, between the minimum and maximum values, the piecewise-linear function interpolating the loading vs isomass area plot (orange). We remark that the application of the Numerical Integration does not aim at reconstructing the erupted mass, but only the portion deposited over the considered domain (proximal area excluded) without any extrapolation. This is clearly shown by the bias between the results presented in orange and the black line. In contrast, the other reconstruction methods aim at estimating the erupted mass by means of an extrapolation from the fitting curves. Recently, different techniques have been introduced (Daggitt et al. 2014; Bonadonna and Costa 2013; Biass et al. 2013) in order to quantify the interval of confidence of the fitting parameters and consequently of the estimated mass. Here, we want to 

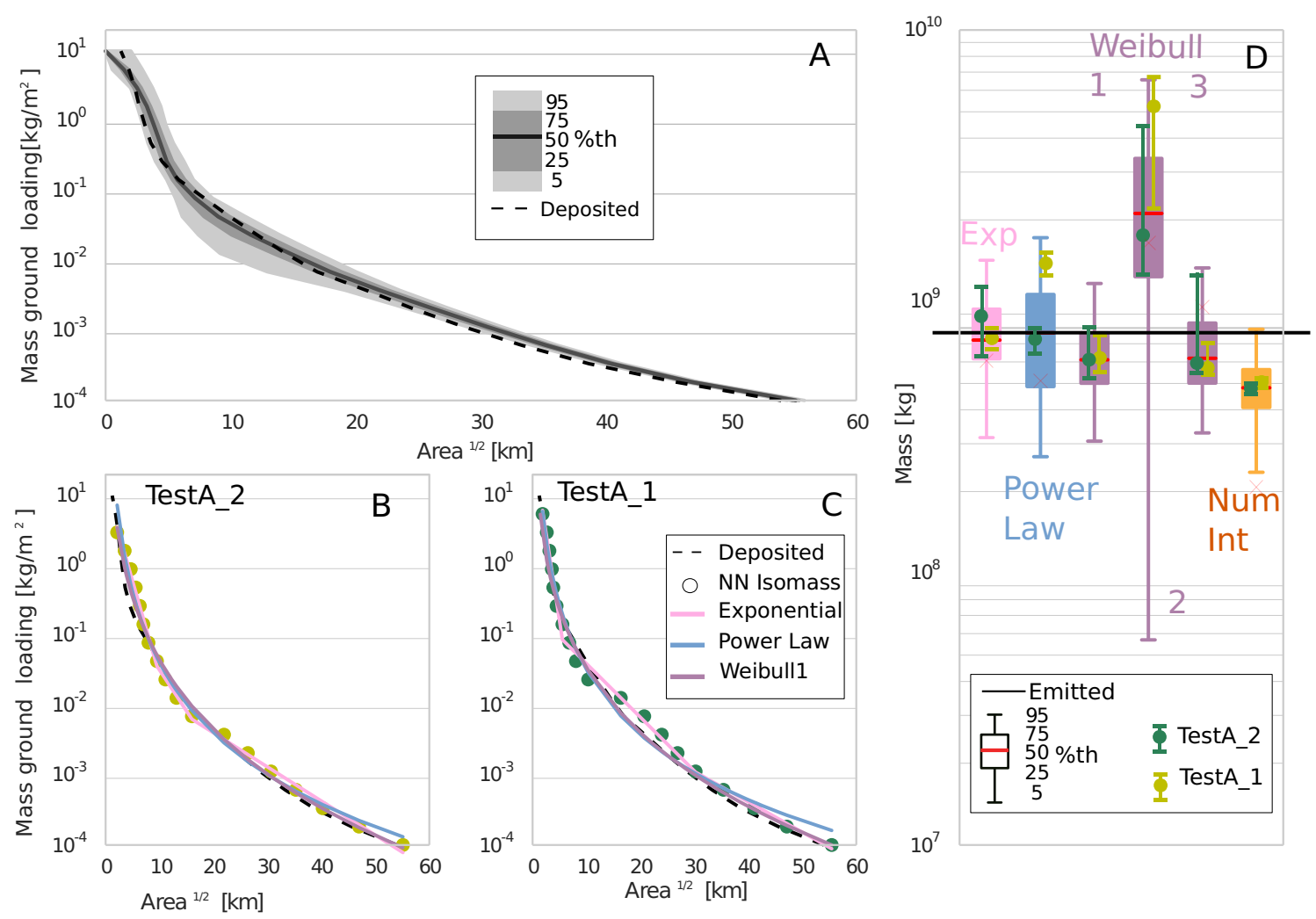

Fig. 6 a Semi-log plot of loading mass $\left(\mathrm{kg} / \mathrm{m}^{2}\right)$ versus sqrt Area $(\mathrm{km})$. Dashed line is calculated using the entire dataset, whereas dark line indicates the area representing the median $(50 \%)$ of the isomass area values obtained with 2000 sampling tests. Gray and light-gray areas represent respectively the $25^{t h}-75^{\text {th }}$ and the $5^{\text {th }}-95^{\text {th }}$ percentiles intervals of calculated isomass areas. $\mathbf{b}$ and $\mathbf{c}$ Green and yellow circles correspond to the tests presented in Fig. 4. For each test colored circles represent the values calculated from the reconstructed deposit. An examples of best fit functions is shown for TestA_1 and TestA_2: Exponential (pink), Power-law (blue), and Weibull1 (purple). In d, the

compare how these intervals of confidence for erupted mass differ from errors associated with incomplete sampling, as discussed above. To this aim, we use a Monte Carlo method, perturbing the data with a random uniform error on isomass squared root areas. A range of $\pm 10 \%$, similar to the uncertainty estimated in Klawonn et al. (2014a) when drawing isopach by hand, is used. Afterwards, we express the confidence interval with the $5^{\text {th }}$ and $95^{\text {th }}$ percentiles (see error bar in Fig. 6). We can see, from Fig. 6d, how for TestA_1 Power Law and Weibull2 the erupted mass, represented by the black line, is well outside the confidence intervals whereas for the other methods it lies within the intervals.

\section{Deposited grain size distribution}

In analogy with the previous section, here we first compare for each size the emitted mass $\left(\mathrm{EM}_{i}\right)$ with the deposited $\left(\mathrm{DM}_{i}\right)$ obtained from an exact integration of the simulated results of a statistical analysis conducted over the 2000 sampling tests are presented for different methods: Exponential, (pink), Power-law (blue), and Weibull 123 methods (purple). In addition, also a Numerical Integration (Num Int) of the reconstructed deposit using the NN is presented (orange). The thick gray line represents the emitted mass median value. The $5^{\text {th }}-95^{\text {th }}$ intervals are also reported. As a reference, the black line represents the erupted mass. For TestA_1 and TestA_2 the error bars express the estimated uncertainty obtained with a Monte Carlo method

deposit for the 23 grain size classes. Afterwards, results are compared with the TGSD obtained using the commonly adopted Voronoi tessellation method, applied to the 2000 sampling tests.

Figure 7a shows deposited mass, expressed as percentages of the emitted mass, obtained with the exact integration over four spatial domains (represented by different colors). Blue bars correspond to the deposit integrated over the whole computational domain. Other bars represent smaller domains, obtained by isolating two squares centered on the vent with side length of 2 (Subdomain1) and $4 \mathrm{~km}$ (Subdomain2), and they can be seen as representative of samplings performed excluding very-proximal regions around the vent. Deposited mass $\left(\mathrm{DM}_{i}\right)$ for $\phi \leq 3$, reaches $100 \%$ of the emitted one $\left(\mathrm{EM}_{i}\right)$. For $\phi=4$, this percentage reduces to about $90 \%$ and abruptly down to $15 \%$ for $\phi=5$. Finest simulated class is almost absent in the computed deposit. Results obtained excluding the material deposited inside a square centered on the vent with a side smaller than $2 \mathrm{~km}$ 
Fig. 7 a Modeled Deposited masses $\left(\mathrm{DM}_{i}\right)$ expressed as percentages of the emitted mass $\left(\mathrm{EM}_{i}\right)$ for each simulated grain-size. Different colors correspond to different spatial deposit domains. Blue bars correspond to the whole computational domain.

Subdomain_1 and Subdomain_2 are obtained excluding a square centered on the vent with side length of $4 \mathrm{~km}$ (orange) and $2 \mathrm{~km}$ (light blue), respectively. b The ratio between the deposited and emitted mass is plotted as function of minimum loading considered. Different colors correspond to different thresholds: 0.001 (orange), 0.01 (green), and 0.1 (red) $\mathrm{kg} / \mathrm{m}^{2}$.

The dark blue corresponds to the whole computational domain (i.e., no threshold)
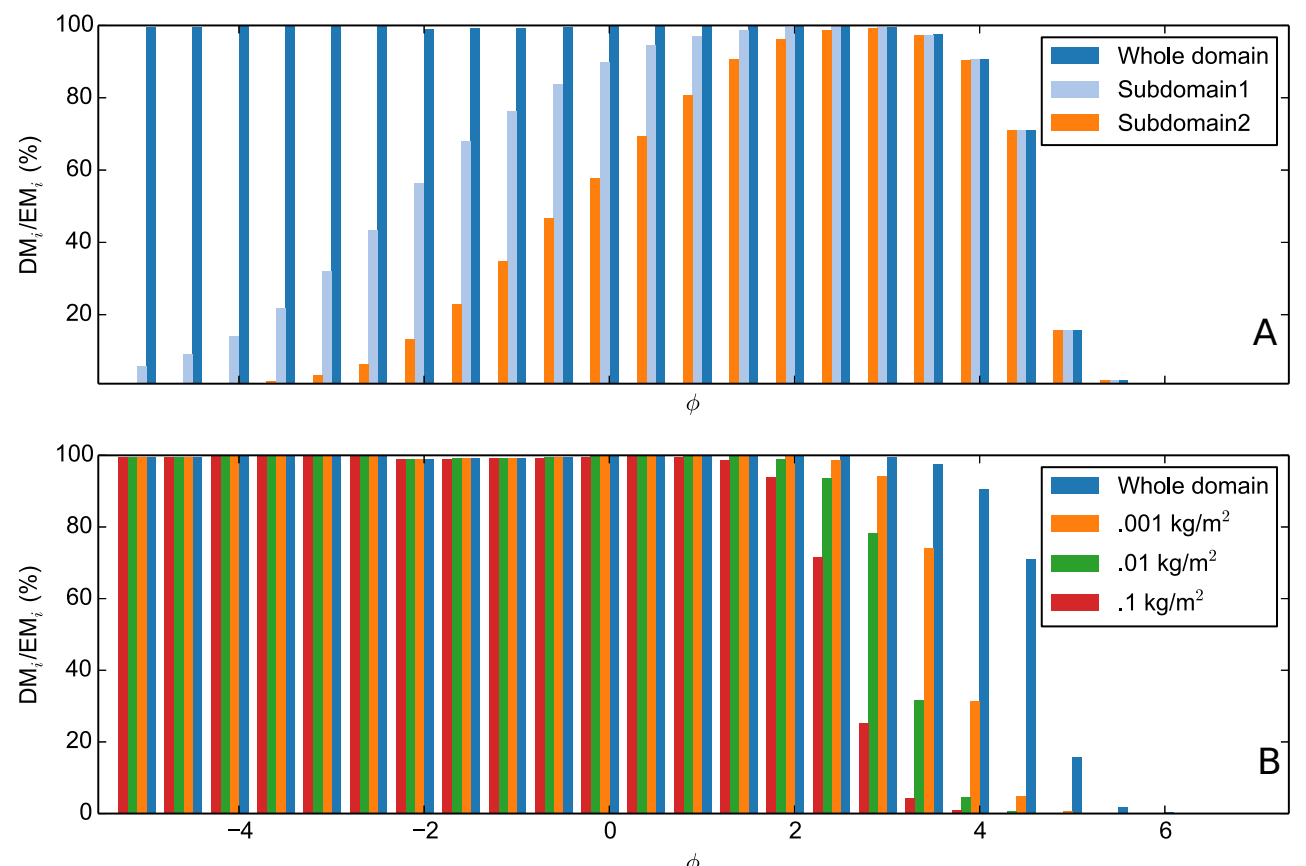

(light-blue bars) classes coarser than $\phi(2)$ are progressively underestimated down to $6 \%$ for $\phi(-5)$. This effect is more visible for Subdomain1 (orange bars) where all $\phi<3$ are underestimated in the deposit, and $\mathrm{DM}_{t o t}$ is only $22 \%$ of $\mathrm{EM}_{\text {tot }}$.

As expected, the deposited mass estimation strongly depends also on the minimum loading (hereafter referred as threshold) considered for the integration: the higher the threshold, the larger the underestimation of deposited mass. Figure $7 \mathrm{~b}$ presents for each simulated grain-size the deposited mass $\mathrm{DM}_{i}$ when different thresholds are considered. Classes in the $\phi$ range interval $[1,2]$ are underestimated of about $5-10 \%$ considering a $0.01 \mathrm{~kg} / \mathrm{m}^{2}$ threshold (orange bars); these percentages rise to $30-60 \%$ when 0.1 $\mathrm{kg} / \mathrm{m}^{2}$ threshold is considered (red bars in Fig. 7b).

As shown in Fig. 7a, for the investigated Scenario, a large amount of the emitted mass for classes $\phi>5$ is advected out the domain (up to $90 \%$ ).

In order to better highlight the depositional patterns for particles of different size, Fig. 8 shows the computed loading contours at the end of the simulation for two different classes: (a) $\phi=3$ and (b) $\phi=5$. For both classes, red isomass lines enclose the area with loading larger than the $50 \%$ of the maximum loading over the domain. In this way, we can quantify for each class both the spreading of the entire deposit and the amount of mass close to the peak location. Figure $8 \mathrm{c}$ reports this information using different markers size as a function of the area enclosed by the isomass curve. In addition, the mean distance from the vent is calculated for each class averaging the distance of the cells within the isomass curves. The color is the loadings associated with the contours. Pink area on the background of panel $\mathrm{C}$ denotes the distance at which ash particles reach the domain border. Due to the lower settling velocity, smaller particles are carried farther and diffuse more by the action of the wind. These two effects are respectively visible in the increase of the mean peak distance from the vent and in the increase of the corresponding isomass area, with the consequent reduction of the maximum loading for the finer classes.

As we have already shown, the effect of the domain restriction drastically reduces the amount of fine classes deposited on such domain. This is well visible in Fig. 8c for classes finer than $\phi=5$ where the peak is leaving the domain border. Therefore, the fine material found on the ground is mostly coming from the margin of the column. The cut-off effect due to a limited domain is not easy to overcome, in fact the area interested by the fallout of particle finer than $\phi=5$ in the case of the described Scenario is larger than $10^{6} \mathrm{~km}^{2}$. However, the spatial distribution of small class is more homogeneous due to the larger diffusion. As a direct consequence, for a smaller class, the error committed using the interpolation techniques for reconstruct $\mathrm{DM}_{i}$ is small.

\section{Comparison with the Voronoi technique}

We test here the Voronoi technique described in "Grainsize distribution" for reconstructing the TGSD. The first step is to fix the deposit extent, adding deposit zero values to the original dataset. We remark that fixing zero values is a strong assumption because, as shown in Fig. 8, zeros 


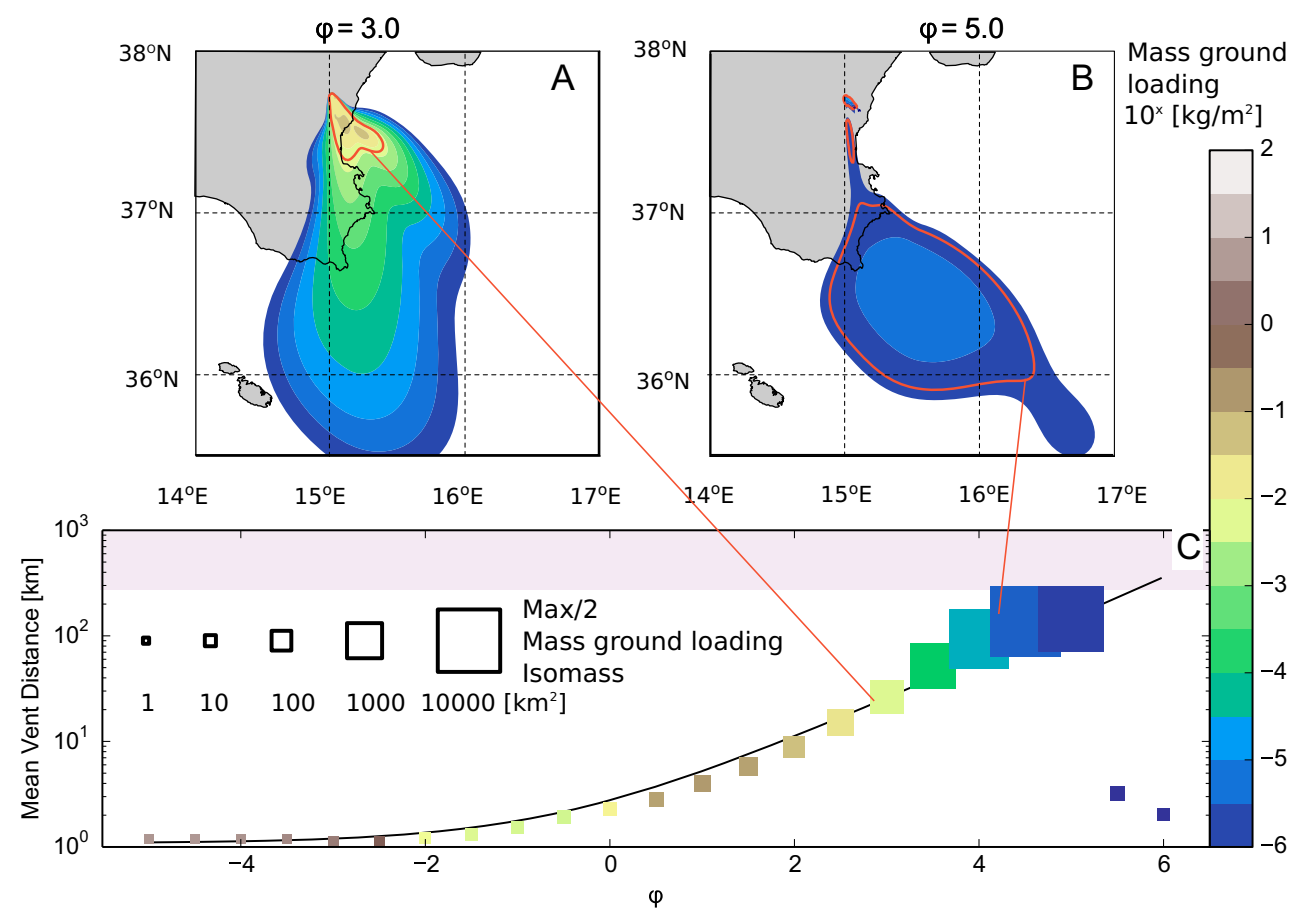

Fig. 8 Computed loading contours at the end of the simulation for different classes: $\mathbf{a} \phi=3$ and $\mathbf{b} \phi=5$. Red isomass lines enclose the area with loading larger than the $50 \%$ of the maximum ("peak"). In panel c, the mean distance from the vent, obtained averaging the cells with loading larger than the $50 \%$ of the maximum (square), is plotted for each class. The dimension of the symbol represents the corresponding cells area $\left(\mathrm{km}^{2}\right)$ and the color the loading

are not the same for each class. For our purposes, here we fix the zeros of the simulated deposit to correspond to the $10^{-2} \mathrm{~kg} / \mathrm{m}^{2}$ isomass contours (about $0.01 \mathrm{~mm}$ thickness, assuming a deposit density of $1000 \mathrm{~kg} / \mathrm{m}^{3}$ ). Finer particles deposited mass estimation strongly depends on the thresholds defining the external boundary of the deposit, and therefore by the zero position (see Fig. 7). Figure 9 shows the result of Voronoi tessellation applied to the 2000 sampling tests. Since Voronoi is an interpolation technique (piecewise constant), we can calculate the deposit mass for each class. Results are shown in Fig. 9a where for each class the reconstructed deposited mass obtained with the Voronoi technique $\left(D M_{i}^{*}\right)$ is expressed as a percentage of the emitted. Dark gray line represents the median of reconstructed TGSDs obtained with Voronoi technique. Gray and light gray areas are respectively the $25^{\text {th }}-75^{\text {th }}$ and the $5^{\text {th }}-95^{\text {th }}$ percentile intervals. Dashed line represents the deposited TGSD obtained with the exact integration. As examples, results for TestA_2 and TestA_1 are plotted with green and yellow circles, respectively. Standard deviations of the percentages reconstructed with the Voronoi method are also reported for each class with red crosses. In Fig. 9 b, we plot the reconstructed TGSD expressed as wt \%. As reference, we plot the emitted (black solid line) and deposited $\left(\mathrm{kg} / \mathrm{m}^{2}\right)$. The pink area on the $y$-axis of panel $\mathbf{c}$ denotes the distance at which ash particles reach the domain border. The black line is obtained by fitting the mean distance as a function of the particle diameters expressed in meters (d). The resulting approximation is given by the formula $f(d)=0.0002 \cdot d^{-1.3}+1$. This relation can be used to find the best distance from the vent for sampling the class peak

(dashed line) TGSD. The orange line represents the mass deposited over the considered subdomain resulting from fixing zeros and sampling at a certain distance from the vent (corresponding to the orange bars on Fig. 7a, b).

On average Voronoi reconstructs well the deposited mass over the considered area (orange line) but can present artificial mode on the reconstructed TGSD due to the piecewise approximation. In fact, different classes, having different settling velocities, will generate peaks in the deposit at different distances from the vent (Fig. 8c). Indeed, if a sampling point is close to a peak of a specific class, this maximum value of the deposit will be extended over the entire Voronoi cell. This could have the final effect of overestimating the reconstructed class mass as visible in Fig. 9a for $\phi(3)$. Due to diffusion, finer particles $(\phi>2)$ present a more uniform distribution at the ground and a smaller maximum load. For this reason, it is easier to sample points with a loading close to the maximum value and also a piecewise constant method, as Voronoi, well approximates the deposited mass. Conversely, for coarser particles, the area with a loading higher than $50 \%$ of the peak is smaller (see Fig. 8c) and the probability to have a sample within this area is smaller, resulting in a larger variability in the results. It is also worth to note that the modes observed 

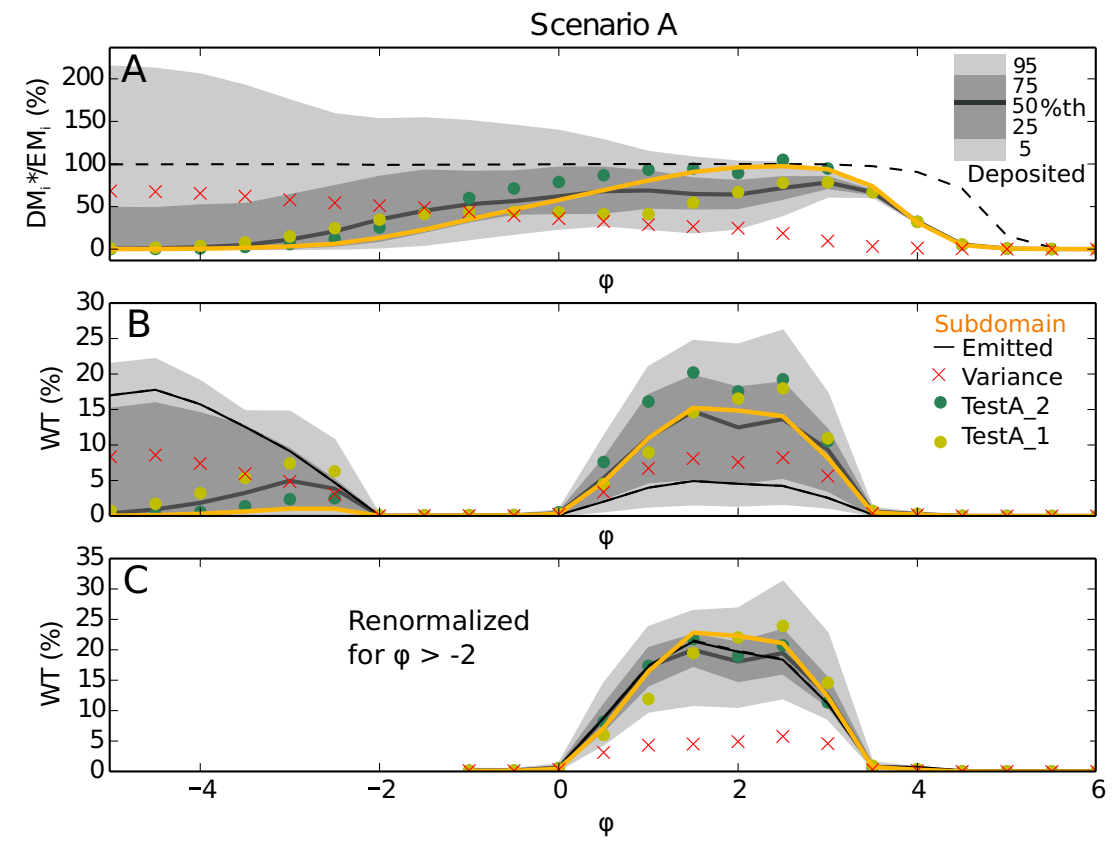

Fig. 9 Statistical analysis conducted applying the Voronoi method to the 2000 sampling tests. For each class, the gray line represents the median and the gray area represents the interval of confidence between the $95^{\text {th }}-5^{\text {th }}$ (light gray) and the $25^{\text {th }}-75^{\text {th }}$ percentile (gray). Green and yellow dots show the value obtained for example tests TestA_1 and TestA_2. As a reference, the mass fraction computed from the

in Fig. 9b, associated with the samples and the reconstruction technique, are in the relative amount of mass and not in the absolute value, and thus they can also be due to an underestimation of the other classes, as visible in Fig. 9a.

For the classes corresponding to the mode, a larger gap is present between the $5^{\text {th }}$ and the $95^{\text {th }}$ percentiles (lightgray area). A large variability in the results obtained for the different sampling tests is also indicated by the large standard deviation. Conversely, for finer particles $(\phi>3)$, a better accordance between values obtained with the exact integration and values reconstructed with the Voronoi technique is found. For these classes, also the standard deviation and the gap between the $5^{\text {th }}$ percentile and the $95^{\text {th }}$ percentile are small, and thus the reconstruction is more stable with respect to the choice of sampling points. Consequently, Voronoi seems reproducing well the deposited mass if we restrict our analysis to $\phi(-2)$, as visible in Fig. 8c.

\section{Discussion}

The analysis presented in the previous sections confirms that inferring quantitative data from the deposits can be very difficult and a large uncertainty affects the results. Estimated values can be far from representing a full picture of the initial eruptive condition at the vent. On the one hand, the reconstruction of the total mass and the grain size whole deposit (dashed black line) and the emitted mass fraction are also reported (black line). In a, the deposited mass reconstructed with Voronoi is expressed as a function of the emitted $\left(\mathrm{DM}_{i}^{*} / \mathrm{EM}_{i}\right)$. In $\mathbf{b}$, the same analysis is conducted for the WT\%. In c, the deposited mass is renormalized by all the class finer than $\phi(-2)$

with an exact integration over the considered computational domain (area $7.5 \times 10^{2} \mathrm{~km}^{2}$ ) shows that, for finer particles, a large amount of the emitted mass is not found at the ground (see Fig. 5b). Precisely, $78 \%$ of particles with $\phi>4$ is leaving the domain. On the other hand, information on coarser particles is partially lost when very proximal area is excluded (Fig. 7a).

A combination of these two effects, here obtained considering a loading larger than $0.01 \mathrm{~kg} / \mathrm{m}^{2}$ (roughly corresponding to $0.01 \mathrm{~mm}$ ) and excluding an area within about $2 \mathrm{~km}$ from the vent, causes an underestimation of the deposited mass up to about $70 \%$. In this case, the two constraints on the integration domain adopted to figure out the TGSD can reflect a reasonable minimum value sampled in the field and the objective difficulties in reaching areas very close to the vent.

The underestimation reflects also in an almost uni-modal reconstructued TGSD, where the tails are both depleted with respect to the initial ones. We remark that these results are not an effect of the procedure, since no extrapolation techniques are used. The mass underestimation only depends of the choice of the integration domain, although quite extended in this study.

Results are obtained for a $\phi$ range spanning from -5 to 6 , but the same investigations, considering finer particles, would produce similar outcomes. Similar results, on modifying the sampling region by excluding a proximal area, 
have been found on Andronico et al. (2014a) whereas the mass lost was estimated to be $22 \%$ of the EM.

Deposit information is further degraded when inferred from a finite number of sampling values by using reconstruction methods. In general, despite the large number of samples considered for each sampling test (50 points are considered a very well sampled deposit), the mass values obtained with Exponential, Power-law and Weibull methods show a large variability and, for a significant percentage of tests, an underestimation of the erupted mass (Fig. 4d).

On average, Exponential and Weibull1 fitting methods seem to produce more stable results than the Power Law and other Weibull functions providing a better estimate of erupted mass. Numerical integral provides a smaller standard deviation within the 2000 sampling tests performed.

When the Voronoi technique is used, the TGSD presents fictitious modes in the resulting distribution (Fig. 9) and a large variability affects the results depending on the choice of the sampling points. This is mostly due to a problem of the deposit exposure and not on the particular choice of the averaging strategy (here Voronoi).

\section{Best sampling strategy}

Based on our study on the column model, columns height is weakly dependent the emitted TGSD. Consequently, from Fig. 8c, we can conclude that for each class the peak distance from the vent is minimally depending on the emitted percentage. Similar results have been found using analytical model for mono-disperse plume released from high altitude (Tirabassi et al. 2009). Because the peak distance, for a fixed column height, is not depending on the emitted mass but only on the atmospheric condition, we can easily estimate it. This would help to find the best sampling region to reconstruct the eruptive scenario reducing the number of sampled points (see also Spanu et al. 2015; Costa et al. 2016). In fact, using Fig. 8c, we can obtain for each class the distance from the vent where to sample to measure the loading peaks. For example, to correctly estimate the deposited mass $\phi(1)$, we should sample at least one point at $3 \mathrm{~km}$ from the vent. This suggests an optimal sampling strategy where we collect points along the main dispersal axis with a growing distance from the vent as shown with the black line in Fig 8c. For coarser classes, only a very small part of the emitted material is deposited in the considered domain (see Fig. 7). When we consider the number of particles for unit area, instead of the mass, we found less than one particle per square meter already at $2 \mathrm{~km}$ away from the vent with $\phi<(-4)$. Thus, the probability to sample coarse particles at these distances is really small and this produces a large variability in the reconstruction of the emitted mass. One solution to reduce this uncertainty is to collect more points on the same region to make the statistic more robust. This will also increase the probability of sampling a peak. As we can see in Fig. 8c, the peak isomass area is a function of the particles size. For coarse classes $(\phi<-2)$, the peak is concentrated in a small area consequently it is more difficult to locate.

\section{Correction factors}

Mass deposited over a limited domain always provides an underestimation of the emitted mass, depending on the domain size. Thus, when numerical techniques are used to compute for each class the mass deposited over a fixed domain, there is a need for some correction factors to fill the gap between the estimated and the emitted eruptive parameters. For the scenario investigated, the results presented in Fig. 10 show for the different classes and for different domain sizes the ratio between the deposited and the emitted mass, thus providing the desired correction factors. In order to generalize our results to other scenarios, we conduct a sensitivity study varying some ESP over 4000 runs. In Fig. 10, the ratio between deposited and emitted mass, as a function of column height and particle size, is plotted for four different domains: (a) $2 \times 2 \mathrm{~km}^{2}$, (b) $4 \times 4 \mathrm{~km}^{2}$, (c) $200 \times 200 \mathrm{~km}^{2}$, and (d) $400 \times 400 \mathrm{~km}^{2}$. Domains are centered on the eruptive vent; consequently, they correspond respectively to a maximum vent distance of 1,2,100, and $200 \mathrm{~km}$. Each circle represents a simulated scenario initialized with a random sampling of plume radius, exit velocity and TGSD. Initial velocity ranges between 10 and $160 \mathrm{~m} / \mathrm{s}$ and the radius between 5 and $55 \mathrm{~m}$. The TGSD is parametrized as a bi-modal distribution where $\mu_{1,2}$ and $\sigma_{1,2}$ are varied in the intervals $[-3,5]$ and $[0.5,6]$, respectively. Variables are selected using a Latin hypercube sampling (LHS) strategy (McKay et al. 1979). For a fixed column height and a fixed class, since the ratio $\left(\mathrm{DM}_{i} / \mathrm{EM}_{i}\right)$ is varying minimally with the emitted TGSD, we can use it to define a correction factors to account for the fraction not deposited over the considered domain. In this way, we can relate the deposited TGSD with the emitted one.

In Fig. 11b, we show two examples explaining how to apply the correction factors for a hypothetic scenario with a $2000 \mathrm{~m}$ agl column height. First of all, we collect the sampling points, using the strategy presented in "Best sampling strategy" and two different intervals for the distances from the vent: $[1,100] \mathrm{km}(\mathrm{A})$ and $[2,100] \mathrm{km}(\mathrm{E})$. Then, we calculate for each class the mass deposited over the considered domains (Fig. 11b, f) using the NN method, without the need to fix deposit zero values. Using the coefficients of Fig. 10, we calculate the correction inverse factors considering the ratio $\mathrm{DM}_{i} / \mathrm{EM}_{i}$ over the considered domains Fig. 11c, g. For example, for Fig. 11c, where the sampling distance is ranging between 1 and $100 \mathrm{~km}$, the coefficients of Fig. 10a for 0 and $1 \mathrm{~km}$ are subtracted from the coefficients of Fig. 10c for 0 and $100 \mathrm{~km}$. The gray area represents 
Fig. 10 Ratio of deposited mass over the emitted mass $\left(\mathrm{DM}_{i} / \mathrm{EM}_{i}\right)$ for different class sizes in the $\phi$ interval $[-5,6]$ (different color), expressed as a function of column height. Each dot represents a different run. Correction inverse factor $\left(\mathrm{DM}_{i} / \mathrm{EM}_{i}\right)$ are calculated for different domain size, respectively. a $2 \times 2$, b $4 \times 4$, c $200 \times 200$, and d $400 \times 400$. Domains are centered on the eruptive vent; consequently, they correspond respectively to a maximum vent distance of 1,2 , 100 , and $200 \mathrm{~km}$. The red box is a reference marker for a column height of $2000 \mathrm{~m}$
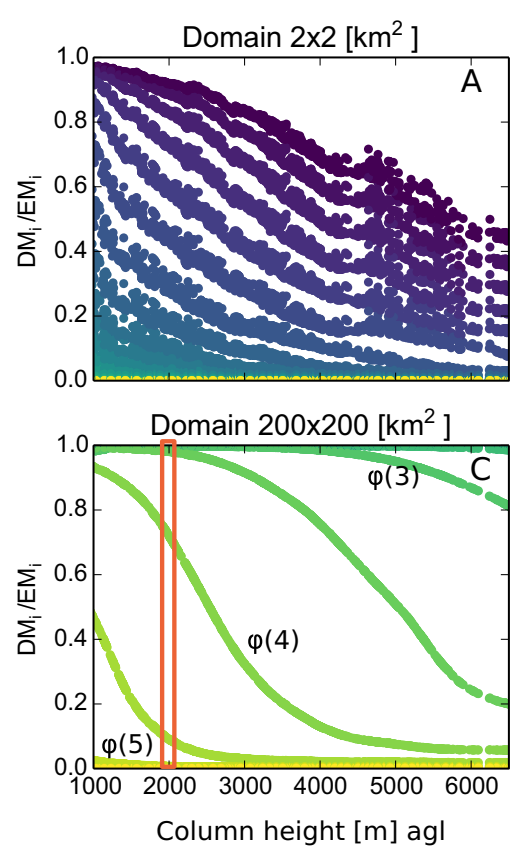

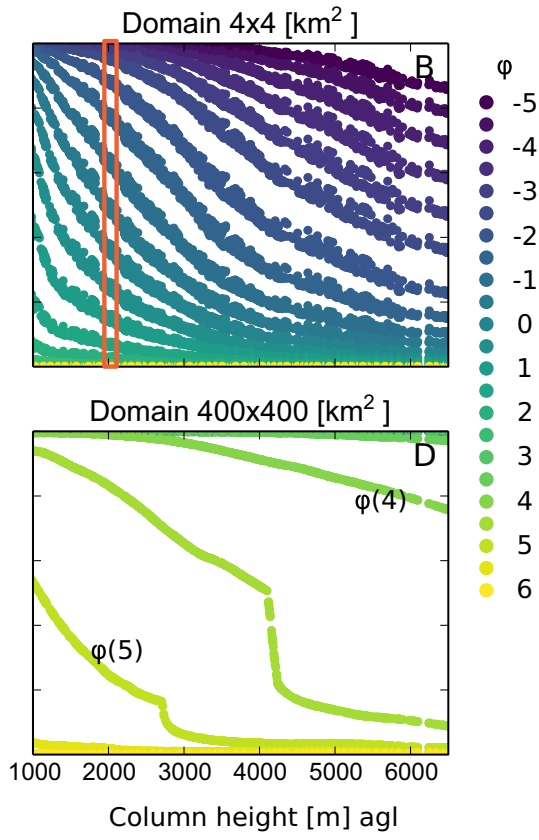

the variation between the minimum and maximum values obtained varying all the eruptive parameters and selecting only column heights within a 100-m interval around the estimated value (2000 m agl). Finally, dividing each class mass by the corresponding correction factor, we obtain an estimation of the emitted mass for each class with an interval of confidence ([Max, Min]) Fig. 11d, h. When a class is not represented in the samples, as for particles coarser than
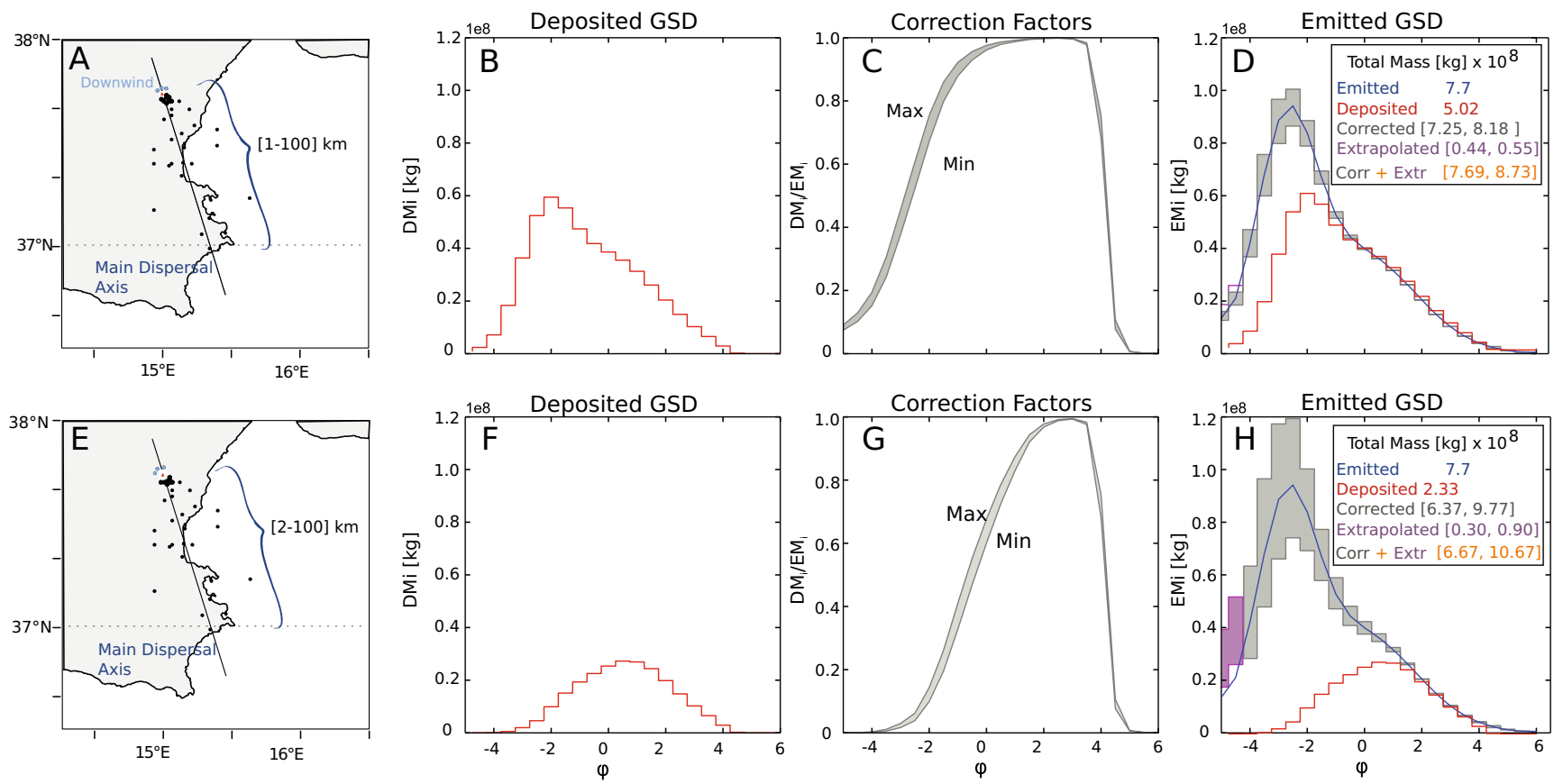

Fig. 11 Two examples of best model-sampling strategy are shown for an eruptive event with a column of $2000 \mathrm{~m}$ and two sampling distances from the vent: $[1,100] \mathrm{km}$ in (a) and $[2,100] \mathrm{km}$ in (d). Panels b and f are plotted the deposited TGSDs obtained applying NN to the two sampling datasets. In $\mathbf{c}$ and $\mathbf{g}$, the corresponding correction inverse factors are calculated for the assumed scenario with a column of $2000 \mathrm{~m}$ agl, considering the respective domain limitations. The minimum and

the maximum factors are calculated varying the ESP as described for Fig. 10. In $\mathbf{d}$ and $\mathbf{h}$, we show the TGSD obtained with the correction factors. The gray area represents the interval between the minimum and the maximum estimated mass. The blue line is the original emitted distribution. The purple area is the extrapolated value obtained using a fitting on the tail. As a reference, the total EM is compared with reconstructed values 
$\phi=-4$ for the second example (see Fig. 11f), the direct use of the correction factors is difficult. Consequently, we suggest extrapolating from the other classes the information presented on the corrected TGSD. As suggested in several studies on rock fragmentation (Hartmann 1969; Turcotte 1986; Kaminski and Jaupart 1998; Kueppers et al. 2006; Perugini and Kueppers 2012; Girault et al. 2014), particles number follows a power law distribution. Under this assumption, we can partially recover the mass of coarser particles by extrapolating the particles number with a power law (see purple area in Fig. 11h).

This method also allows an estimation of the emitted mass by summing the results obtained for all the classes (see Fig. 11d, h). For a sampling distance within 1 and $100 \mathrm{~km}$ from the vent (Fig. 11a), the deposited mass $\mathrm{DM}_{t o t}$ only represents the $70 \%$ of the emitted one, whereas the interval provided by our method correspond to 90 and $112 \%$ of the emitted mass. For the second example (Fig. 11e), where the sampling points are collected within 2 and $100 \mathrm{~km}$ from the vent, the deposited mass represents only the $30 \%$ of the emitted, whereas our method gives an interval corresponding to 82 and $120 \%$ of the real value. Despite the effect of excluding a proximal area region is smaller for higher columns, for a $6000 \mathrm{~m}$ agl column only $10 \%$ of $\phi(-5)$ is still depositing outside the proximal region (see Fig. 10b). In the auxiliary material, we provide a table with more examples of correction inverse factor for different column height.

The same technique can be adopted to estimate information losses over a generic domain, for example, when the median region or areas above the sea are missing. However, when applying the method we need to be careful in considering the uncertainty associated with the reconstruction techniques applied to samplings dataset (in our examples NN) because this error will affect directly our estimate interval. We remark that approximation errors are decreasing with the number of the collected sample, whereas the bias between the emitted and deposited mass only depends on the considered domain.

\section{Aggregation}

As stated in several papers (Carey and Sigurdsson 1982; Bonadonna et al. 2016; Taddeucci et al. 2011; Brown et al. 2012b; Klawonn et al. 2014a), particle aggregation can significantly affect the dispersal process and the tephra depositional pattern. For this reason, we extend our study considering a simple aggregation process occurring within the margin of the column, as proposed by Textor et al. (2006). To this aim, we adopt a model based on Cornell et al. (1983) and Sulpizio et al. (2012), where a fixed percentage $(10,20$, and $50 \%)$ of emitted mass for $\phi>2$ aggregates as $\phi=2(250 \mu \mathrm{m})$ particles. As a first approximation, particle density remains the same of the aggregating class. As stated by Brown et al. (2012b), aggregates due to collisions at the ground are supposed to be found as completely break apart in the deposit. Figure 12 shows the effect of three different aggregation ratio: (a) $10 \%$, (b) $20 \%$, and (c) $50 \%$, respectively. The amount of deposited fine particles increases almost linearly with aggregation, and consequently, the fraction leaving the domain is reduced (for the scenario the $78 \%$ of particles with $\phi>4$ leaving the domain change respectively in 70,62 , and $39 \%$ for the three aggregation ratio considered). On the other hand, information on
Fig. 12 Correction inverse factors $\left(\mathrm{DM}_{i} / \mathrm{EM}_{i}\right)$ calculated for different classes size (different colors) assuming an aggregation model with different aggregation ratios of a 10, b 20, and c $50 \%$, respectively

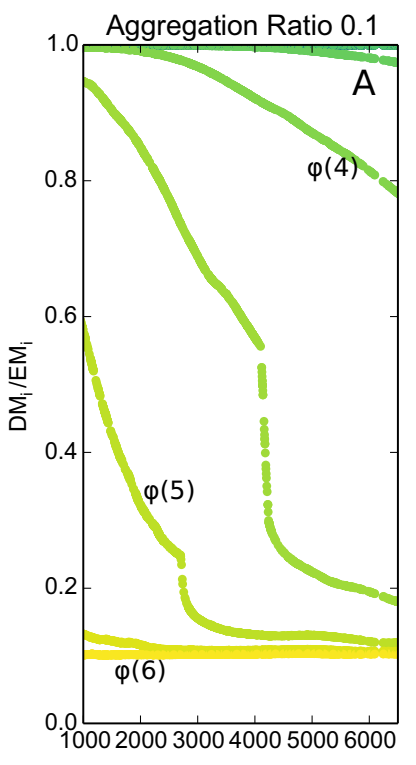

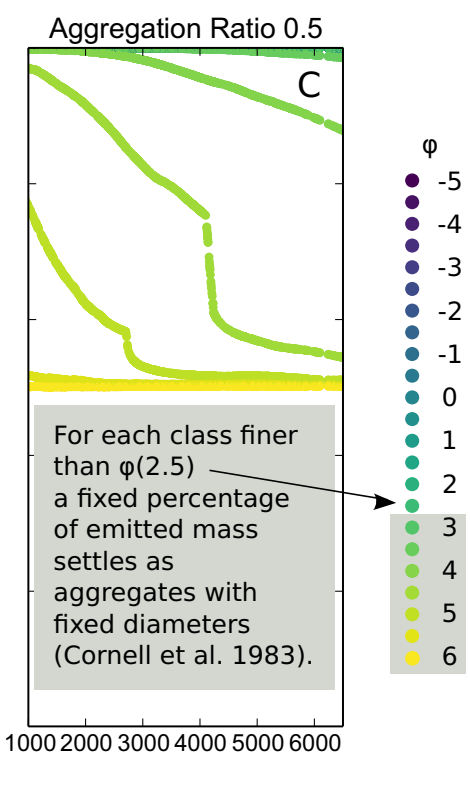


coarser particles is partially lost when very proximal area is excluded (Fig. 7a). Nevertheless, even when 10 and $20 \%$ of aggregation is considered, $\phi>5$ classes deposit only as aggregates in the considered domain. Indeed, the observation of a particular class in the deposit only as aggregate could be erroneously interpreted as evidence that $100 \%$ of the emitted mass for the observed class aggregated during the transport. This reveals how using, for a single class size, the amount of aggregated and non-aggregated particles on the deposit, as indicative of the aggregation ratio, can be misleading. Clearly, aggregation plays an important role on the estimated uncertainty, as we can see from Fig 12, but only for small particles affected by aggregation process. Analyses conducted on larger particles, since not influenced by aggregation, are still valid.

Since we obtained our results using a numerical study, they are clearly dependent on model assumptions. However, we tested the dependency on settling velocity, factor shape and particles density, and results are poorly sensitive to those parameters.

\section{Conclusion}

A numerical strategy has been adopted in order to better understand a deposit footprint and its thoroughness in quantifying eruptive source parameters like mass and TGSD. Starting from a set of loading measurements collected after the 24 November 2006 Etna eruption, we generated a full tephra deposit, by applying an inversion method to the dispersal code VOL-CALPUFF. We analyzed the deposited mass and the deposited TGSD by using an exact integration over the computational domain. Then these values were compared with values estimated with standard reconstruction techniques showing that:

- Deposited mass was a function of considered domain and exact integration allowed to quantify the underestimation with respect to the emitted mass. When the deposited mass was integrated over a distance of 1 and $100 \mathrm{~km}$ from the vent only $30 \%$ of the emitted mass was found on the ground.

- Even by using a large and well-distributed dataset of sampled points (50 points) over the modeled domain, large errors can affect the results. Reconstruction techniques, performed over 2000 different sampling tests, showed a gap in the mass values up to an order of magnitude between the $5^{\text {th }}$ and the $95^{\text {th }}$ percentile. Besides, estimated confidence intervals were not representative of committed errors.

- Large standard deviation values and large relative errors affected reconstructed TGSD obtained in case of poorly exposed deposits. In particular, the emitted fractions of coarse and fine particles were generally underestimated underrating the hazard associated with volcanic airborne particulate. Furthermore, when the fractions obtained with the Voronoi technique were rescaled with the total emitted mass, median classes were always overestimated in mass.

- We proposed a new method to reconstruct the emitted TGSD and the emitted mass starting from single classes measurements and column height observations. We used a sensitivity study on eruptive parameters to generalize the analysis so far depending on the eruption scale and assumed TGSD.

- Column height showed to be weakly dependent on the TGSD emitted. Consequently, for a fixed column height, for each class the distance from the vent of the maximum loading is independent from the emitted percentage. This provides a useful criterion to sample a deposit in order to reduce the uncertainty in the TGSD.

Finally, this work showed how, in support of field-based studies, numerical studies represent a useful tool to assess ESP uncertainty.

Acknowledgments This work presents results achieved in the $\mathrm{PhD}$ work of the first author (A.S.), carried out at Scuola Normale Superiore and Istituto Nazionale di Geofisica e Vulcanologia. The activity has been partially funded by the Italian Presidenza del Consiglio dei Ministri Dipartimento della Protezione Civile (Project V1). Further, we should mention ARPA_SIM-CINECA for the LAMI code runs. The manuscript benefited from fruitful discussions with Dr. A. Neri, Dr. S. Engwell and Prof. A.B. Clarke. We wish to thank the Editor Prof. C. Bonadonna, M. Pyle, and two other anonymous reviewers for their constructive comments that greatly improved the quality of the manuscript.

Open Access This article is distributed under the terms of the Creative Commons Attribution 4.0 International License (http:// creativecommons.org/licenses/by/4.0/), which permits unrestricted use, distribution, and reproduction in any medium, provided you give appropriate credit to the original author(s) and the source, provide a link to the Creative Commons license, and indicate if changes were made.

\section{References}

Alidibirov M, Dingwell DB (1996) Magma fragmentation by rapid decompression. Nature 380:146-148. doi:10.1038/380146a0

Andronico D, Branca S, Calvari S, Burton MR, Caltabiano T, Corsaro RA, Del Carlo P, Garfí G., Lodato L, Miraglia L, Muré F., Neri M, Pecora E, Pompilio M, Salerno G, Spampinato L (2005) A multi-disciplinary study of the 2002-03 Etna eruption: insights into a complex plumbing system. Bull Volcanol 67:314-330. doi:10.1007/s00445-004-0372-8

Andronico D, Scollo S, Caruso S, Cristaldi A (2008) The 2002-03 Etna explosive activity: tephra dispersal and features of the deposits. J Geophys Res:113:B4 B04:209. doi:10.1029/2007JB005126 
Andronico D, Scollo S, Cristaldi A, Ferrari F (2009) Monitoring ash emission episodes at Mt. Etna: the 16 November 2006 case study. J Volcanol Geotherm Res 180:123-134. doi:10.1016/j.jvolgeores.2008.10.019

Andronico D, Scollo S, Cristaldi A, Lo Castro MD (2014a) Representivity of incompletely sampled fall deposits in estimating eruption source parameters: a test using the 12-13 January 2011 lava fountain deposit from Mt Etna volcano, Italy. Bull Volcanol 76(10):1-14. doi:10.1007/s00445-014-0861-3

Andronico D, Scollo S, Lo Castro MD, Cristaldi A, Lodato L, Taddeucci J (2014b) Eruption dynamics and tephra dispersal from the 24 November 2006 paroxysm at SouthEast Crater Mt Etna, Italy. J Volcanol Geotherm Res. doi:10.1016/j.jvolgeores.2014.01.009

Arason P, Petersen GN, Bjornsson H (2011) Observations of the altitude of the volcanic plume during the eruption of Eyjafjallajökull, April-May 2010. Earth Syst Sci Data 3(1):9-17. doi:10.5194/essd-3-9-2011

Barsotti S, Bignami C, Buongiorno MF, Corradini S, Doumaz F, Guerrieri L, Merucci L, Musacchio L, Nannipieri L, Neri A, Piscini A, Silvestri M, Spanu A, Spinetti C, Stramondo C, Wegmuller U (2011) SAFER Response to Eyjafjallajökull and Merapi Volcanic Eruptions. In: Commission E. (ed) Let's embrace space' Space Research achievements under the 7th Framework Programme. DG Enterprise and Industry, pp -. http://hdl.handle. net/2122/7646

Barsotti S, Neri A (2008) The VOL-CALPUFF model for atmospheric ash dispersal: 2 Application to the weak Mount Etna plume of July 2001. J Geophys Res 113. doi:10.1029/2006JB0 04624

Barsotti S, Neri A, Bertagnini A, Cioni R, Mulas M, Mundula S (2015) Dynamics and tephra dispersal of violent Strombolian eruptions at Vesuvius: insights from field data, wind reconstruction and numerical simulation of the 1906 event. Bull Volcanol 58:77 7 . doi:10.1007/s00445-015-0939-6

Barsotti S, Neri A, Scire J (2008) The VOL-CALPUFF model for atmospheric ash dispersal: 1 Approach and physical formulation. J Geophys Res. 113:B3 and B03:208 doi: 10.1029/2006JB0 04623

Biass S, Bagheri G, Aeberhard WH, Bonadonna C (2013) TError: towards a better quantification of the uncertainty propagated during the characterization of tephra deposits. Stat Volcanol 1:1-27. doi:10.5038/2163-338X.1.2

Bonadonna C, Biass S, Costa A (2015) Physical characterization of explosive volcanic eruptions based on tephra deposits: propagation of uncertainties and sensitivity analysis. J Volcanol Geotherm Res 296:80-100. doi:10.1016/j.jvolgeores.2015.03.009

Bonadonna C, Costa A (2012) Estimating the volume of tephra deposits: a new simple strategy. Geology 40:415-418. doi:10.1130/G32769.1

Bonadonna C, Costa A (2013) Plume height, volume and classification of volcanic eruptions based on the Weibull function. Bull Volcanol. doi:10.1007/s00445-013-0742-1

Bonadonna C, Houghton BF (2005) Total grain-size distribution and volume of tephra fall deposits. Bull Volcanol 67:441-456. doi:10.1007/ s00445-004-0386-2

Bonadonna C, Scollo S, Cioni R, Pioli L, Pistolesi M (2016) Determination of the largest clasts of tephra deposits for the characterization of explosive volcanic eruptions: report of the IAVCEI Commission on Tephra Hazard Modelling. https://vhub.org/resources/ 870

Bonasia R, Macedonio G, Costa A, Mele D, Sulpizio R (2010) Numerical inversion and analysis of tephra fallout deposits from the 472 AD sub-Plinian eruption at Vesuvius (Italy) through a new best-fit procedure. J Volcanol Geotherm Res 189(3-4):238-246. doi:10.1016/j.jvolgeores.2009.11.009
Branca S, Del Carlo P (2005) Types of eruptions of Etna volcano AD 1670-2003: implications for short-term eruptive behaviour. Bull Volcanol 67(8):732-742. doi:10.1007/s00445-005-0412-z

Brown D, Brownrigg R, Haley M, Huang W (2012a) NCAR Command Language (NCL). doi:10.5065/D6WD3XH5

Brown RJ, Bonadonna C, Durant AJ (2012b) A review of volcanic ash aggregation. Phys. Chem. Earth 45-46:65-78. doi:10.1016/ j.pce.2011.11.001

Burden RE, Chen L, C PJ (2013) A statistical method for determining the volume of volcanic fall deposits. Bull Volcanol 75(6):1-10. doi:10.1007/s00445-013-0707-4

Burden RE, Phillips JC, Hincks TK (2011) Estimating volcanic plume heights from depositional clast size. J Geophys Res 116. doi:10.1029/2011JB008548

Bursik M (2001) Effect of wind on the rise height of volcanic plumes. Geophys Res Lett 18:3621-3624. doi:10.1029/2001GL013393

Bursik M, Jones M, Carn S, Dean K, Patra A, Pavolonis M, Pitman EB, Singh T, Singla P, Webley P, Bjornsson H, Ripepe M (2012) Estimation and propagation of volcanic source parameter uncertainty in an ash transport and dispersal model: application to the Eyjafjallajökull plume of 14-16 April 2010. Bull Volcanol 74:2321-2338. doi:10.1007/s00445-012-0665-2

Bursik M, Sieh K (2013) Digital database of the Holocene tephras of the Mono-Inyo Craters, California. US Geological Survey Data. http://pubs.usgs.gov/ds/758/

Carey SN, Sigurdsson H (1982) Influence of particle aggregation on deposition of distal tephra from the May 18, 1980, eruption of Mount St. Helens Volcano. J Geophys Res 87:7061-7072. doi:10.1029/JB087iB08p07061

Connor LJ, Connor CB (2006) Inversion is the key to dispersion: understanding eruption dynamics by inverting tephra fallout. Stat Volcanol 1:231-242

Cornell W, Carey SN, Sigurdsson H (1983) Computer simulation of transport and deposition of the Campanian Y-5 ash. J Volcanol Geotherm Res 17:89-109. doi:10.1016/0377-0273(83) 90063-X

Corradini S, Spinetti C, Carboni E, Tirelli C, Buongiorno MF (2008) Mt Etna tropospheric ash retrieval and sensitivity analysis using moderate resolution imaging spectroradiometer measurements. J Appl Remote Sens 2(1):023550. doi:10.1117/1.3046674

Costa A, Pioli L, Bonadonna C (2016) Assessing tephra total grainsize distribution: insights from field data analysis. Earth Planet Sci Lett 443:90-107. doi:10.1016/j.eps1.2016.02.040

Daggitt ML, Mather TA, Pyle DM, Page S (2014) AshCalc-a new tool for the comparison of the exponential, power-law and Weibull models of tephra deposition. J Appl Volcanol 3. doi:10.1186/2191-5040-3-7

Degruyter W, Bonadonna C (2013) Impact of wind on the condition for column collapse of volcanic plumes. Earth Planet Sci Lett 377378:218-226. doi:10.1016/j.eps1.2013.06.041

Doms G, Schättler U. (2002) A Description of the Nonhydrostatic Regional Model LM, Part I: Dynamics and Numerics. Deutscher Wetterdienst

Dubosclard G, Donnadieu F, Allard P, Cordesses R, Hervier C, Coltelli M, Privitera E, Kornprobst J (2004) Doppler radar sounding of volcanic eruption dynamics at Mount Etna. Bull Volcanol 66:443456. doi:10.1007/s00445-003-0324-8

Engwell SL, Aspinall WP, Sparks RSJ (2015) An objective method for the production of isopach maps and implications for the estimation of tephra deposit volumes and their uncertainties. Bull Volcanol 77(7). doi:10.1007/s00445-015-0942-y

Engwell SL, Sparks RSJ, Aspinall WP (2013) Quantifying uncertainties in the measurement of tephra fall thickness. J of Applied Volcanology. doi:10.1186/2191-5040-2-5 
Eychenne J, Le Pennec JL (2012) Sigmoidal particle density distribution in a subplinian scoria fall deposit. Bull Volcanol 74(10):22432249. doi:10.1007/s00445-012-0671-4

Fagents SA, Gregg TKP, Lopes RMC (2013) Modeling Volcanic Processes the Physics and Mathematics of Volcanism. Cambridge University Press, Cambridge

Fierstein J, Nathenson M (1992) Another look at the calculation of fallout tephra volumes. Bull Volcanol 54:156-167. doi:10.1007/ BF00278005

Fisher RV (1964) Maximum size, median diameter and sorting of tephra. J Geophys Res 69:341-355. doi:10.1029/JZ069 i002p00341

Folch A (2012) A review of tephra transport and dispersal models: evolution, current status and future perspectives. J Volcanol Geotherm Res 235-236:96-115. doi:10.1016/j.jvolgeores.2012.05.020

Fontijn K, Ernst GGJ, Bonadonna C, Elburg MA, Mbede E, Jacobs $\mathrm{P}$ (2011) The $\sim 4$-ka Rungwe Pumice (South-Western Tanzania): a wind-still Plinian eruption. Bull Volcanol 73(9):1353-1368. doi:10.1007/s00445-011-0486-8

Gasteiger J, Groß S., Freudenthaler V, Wiegner M (2011) Volcanic ash from Iceland over Munich: mass concentration retrieved from ground-based remote sensing measurements. Atm Chem and Phys 11(5):2209-2223. doi:10.5194/acp-11-2209-2011

Girault F, Carazzo G, Tait S, Ferrucci F, Kaminski E (2014) The effect of total grain-size distribution on the dynamics of turbulent volcanic plumes. Earth Planet Sci Lett 394:124-134. doi:10.1016/j.epsl.2014.03.021

Grainger RG, Peters DM, Thomas GE, Smith AJA, Siddans R, Carboni E, Dudhia A (2013) Measuring volcanic plume and ash properties from space. Geol Soc Lond Spec Publ 380(1):293-320. doi:10.1144/SP380.7

Gudmundsson MT, Thordarson T, Hoskuldsson A, Larsen G, jornsson H, Prata FJ, Oddsson B, Magnusson E, Hognadottir T, Petersen N, Hayward CL, Stevenson JA, Jónsdóttir I (2012) Ash generation and distribution from the April-May 2010 eruption of Eyjafjallajökull, Iceland Scientific Report, 2, 572. doi:10.1038/srep00572

Hartmann WK (1969) Terrestrial, lunar, and interplanetary rock fragmentation. Icarus 10(2):201-213

Johnson JB, Aster RC, Kyle PR (2004) Volcanic eruptions observed with infrasound. Geophys Res Lett 31. doi:10.1029/ 2004GL020020

Johnston EN, Phillips JC, Bonadonna C, Watson IM (2012) Reconstructing the tephra dispersal pattern from the Bronze Age eruption of Santorini using an advection-diffusion model. Bull Volcanol 74(6):1485-1507. doi:10.1007/s00445-012-0609-x

Kaminski E, Jaupart C (1998) The size distribution of pyroclasts and the fragmentation sequence in explosive volcanic eruptions. J Geophys Res: Solid Earth 103(B12):29759-29779. doi:10.1029/98JB02795

Kawabata E, Bebbington MS, Cronin SJ, Wang T (2013) Modeling thickness variability in tephra deposition. Bull Volcanol 75(8):114. doi:10.1007/s00445-013-0738-x

Kawabata E, Cronin SJ, Bebbington MS, Moufti MRH, El-Masry $\mathrm{N}$, Wang $\mathrm{T}$ (2015) Identifying multiple eruption phases from a compound tephra blanket: an example of the ad1256 almadinah eruption, saudi arabia. Bull Volcanol 77(1):1-13. doi:10.1007/s00445-014-0890-y

Klawonn M, Frazer LN, Wolfe CJ, Houghton BF, Rosenberg MD (2014a) Constraining particle size-dependent plume sedimentation from the 17 June 1996 eruption of Ruapehu Volcano, New Zealand, using geophysical inversions. J Geophys Res: Solid Earth 119(3):1749-1763. doi:10.1002/2013JB010387

Klawonn M, Houghton BF, Swanson DA, Fagents SA, Wessel P, Wolfe CJ (2014b) From field data to volumes: Constraining uncertainties in pyroclastic eruption parameters. Bull Volcanol 76(7):1-16. doi:10.1007/s00445-014-0839-1

Klawonn M, Wolfe CJ, Frazer LN, Houghton BF (2012) Novel inversion approach to constrain plume sedimentation form the tephra deposit data: Application to the 17 June 1996 eruption of Ruapehu volcano, New Zealand. J Geophys Res 117. doi:10.1029/2011JB008767

Kueppers U, Perugini D, Dingwell DB (2006) Explosive energy during volcanic eruptions from fractal analysis of pyroclasts. Earth Planet Sci Lett 248(3-4):800-807. doi:10.1016/j.eps1.2006.06.033

Kylling A, Kahnert M, Lindqvist H, Nousiainen T (2014) Volcanic ash infrared signature: porous non-spherical ash particle shapes compared to homogeneous spherical ash particles. Atmos Meas Tech 7:919-929. doi:10.5194/amt-7-919-201

Magill C, Mannen K, Connor LJ, Bonadonna C, Connor CB (2015) Simulating a multi-phase tephra fall event: inversion modelling for the 1707 Hoei eruption of Mount Fuji, Japan. Bull Volcanol 77(9):1-18. doi:10.1007/s00445-015-0967-2

Mastin LG (2014) Testing the accuracy of a 1-D volcanic plume model in estimating mass eruption rate: VOLCANIC PLUME MODELS ERUPTION RATE. J Geophys Res-Atmos 119(5):2474-2495. doi:10.1002/2013JD020604

McKay MD, Beckman RJ, Conover WJ (1979) Comparison of Three Methods for Selecting Values of Input Variables in the Analysis of Output from a Computer Code. Technometrics; (United States) 21(2):239-245. doi:10.1080/00401706.1979.10489755

de' Michieli Vitturi M, Neri A, Barsotti S (2015) Plume-mom 1.0: a new integral model of volcanic plumes based on the method of moments. Geosci Model Dev 8(8):2447-2463. doi: $10.5194 /$ gmd-8-2447-2015

Morton BR (1959) Forced plumes. J Fluid Mech 5(151):16. doi: $10.1017 / \mathrm{S} 002211205900012 \mathrm{X}$

Murrow PJ, Rose WI, Self S (1980) Determination of the total grain size distribution in a Vulcanian eruption column and its implications to stratospheric aerosol perturbation. Geophys Res Lett 7:893-896. doi:10.1029/GL007i011p00893

Pardini F, Spanu A, de' Michieli Vitturi M, Salvetti MV, Neri A (2016) Grain size distribution uncertainty quantification in volcanic ash dispersal and deposition from weak plumes. J Geophys Res: Solid Earth 121(2):538-557. doi:10.1002/2015JB012536

Perugini D, Kueppers U (2012) Fractal analysis of experimentally generated pyroclasts: A tool for volcanic hazard assessment. Acta Geophysica 60(3):682-698. doi:10.2478/s11600-012-0019-7

Pfeiffer T, Costa A, Macedonio G (2005) A model for the numerical simulation of tephra fall deposits. J Volcanol Geotherm Res 140. doi:10.1016/j.jvolgeores.2004.09.001

Pyle DM (1989) The thickness, volume and grainsize of tephra fall deposits. Bull Volcanol 51:1-15. doi:10.1007/BF01086757

Rose WI, Bluth GJS, Ernst GGJ (2000) Integrating retrievals of volcanic cloud characteristics from satellite remote sensors: a summary, vol 385. Phil. Trans. R. Soc. Lond. A. doi:10.1098/rsta. 2000.0605

Rose WI, Bonis S, Stoiber RE, Keller M, Bickford T (1973) Studies of volcanic ash from two recent Central American eruptions. Bull Volcanol 37(3):338-364. doi:10.1007/BF02597633

Rose WI, Kostinski A, Kelley L (1995) Real-time C-Band and radar observations of 1992 eruption clouds form Crater Peak, Mount Spurr, Alaska. US Geol Surv Bull 2139:19-26

Sambridge M, Braun J, McQueen H (1995) Geophysical parameterization and interpolation of irregular data using natural neighbours. Geophys J Int 122:837-857. doi:10.1111/j.1365-246X.1995.tb06841.x

Scire J, Robe F, Fernau M, Yamartino R (2000) A users guide for the CALMET Meteorological Model. Earth Tech. http://www.asg.src. com/calpuff/download/download.htm 
Scollo S, Del Carlo P, Coltelli M (2007) Tephra fallout of 2001 Etna flank eruption: Analysis of the deposit and plume dispersion. J Volcanol Geotherm Res 160(1):147-164. doi:10.1016/j. jvolgeores.2006.09.007

Scollo S, Tarantola S, Bonadonna C, Coltelli M, Saltelli A (2008) Sensitivity analysis and uncertainty estimation for tephra dispersal models. J Geophys Res 113. doi:10.1029/2006JB004864

Sibson R (1981) A Brief Description of Natural Neighbor Interpolation, vol 2. Wiley, Chichester

Spanu A, de' Michieli Vitturi M, Barsotti S (2015) Reconstructing eruptive source parameters from tephra deposit: a numerical approach for medium-sized explosive eruptions. arXiv:1509.00386

Sparks RSJ, Bursik MI, Carey SN, Gilbert JS, Glaze LS, Siggurdsson H, Woods AW (1997) Volcanic Plumes. Wiley, New York. http:// eprints.lancs.ac.uk/id/eprint/53491

Spinetti C, Barsotti S, Neri A, Buongiorno MF, Doumaz F, Nannipieri L (2013) Investigation of the complex dynamics and structure of the 2010 Eyjafjallajökull volcanic ash cloud using multispectral images and numerical simulations. J Geophys Res: Atmospheres 118:4729-4747. doi:10.1002/jgrd.50328

Stevenson JA, Millington SC, Beckett FM, Swindles GT, Thordarson $T$ (2015) Big grains go far: understanding the discrepancy between tephrochronology and satellite infrared measurements of volcanic ash. Atmos Meas Tech 8(5):2069-2091. doi:10.5194/amt-8-2069-2015

Sulpizio R (2005) Three empirical methods for the calculation of distal volume of tephra-fall deposits. J Volcanol Geotherm Res 145:3-4. doi:10.1016/j.jvolgeores.2005.03.001

Sulpizio R, Folch A, Costa A, Scaini C, Dellino P (2012) Hazard assessment of far-range volcanic ash dispersal from a violent Strombolian eruption at Somma-Vesuvius volcano, Naples, Italy: implications on civil aviation. Bull Volcanol 74(9):2205-2218. doi:10.1007/s00445-012-0656-3

Taddeucci J, Scarlato P, Montanaro C, Cimarelli C, Del Bello E, Freda CD (2011) Aggregation-dominated ash settling from the Eyjafjallajökull volcanic cloud illuminated by field and laboratory high-speed imaging. Geology 39:891-894. doi:10.1130/G32016.1

Textor C, Graf HF, Herzog M, Oberhuber JM, Rose WI, Ernst GGJ (2006) Volcanic particle aggregation in explosive eruption columns. Part I: Parameterization of the microphysics of hydrometeors and ash. J Volcanol Geotherm Res 150:359-377. doi:10.1016/j.jvolgeores.2005.09.007

Textor C, Graf HF, Longo A, Neri A, Esposti Ongaro T, Papale P, Timmreck C, Ernst GJ (2005) Numerical simulation of explosive volcanic eruptions from the conduit flow to global atmospheric scales. Annals Geophys 48(4):5. http://hdl.handle.net/ $2122 / 942$

Tirabassi T, Tiesi A, Buske D, Vilhena MT, Moreira DM (2009) Some characteristics of a plume from a point source based on analytical solution of the two-dimensional advection-diffusion equation. Atmos Environ 43(13):2221-2227. doi:10.1016/j.atmosenv. 2009.01.020

Turcotte DL (1986) Fractals and fragmentation. J Geophys Res 91(B2):1921-1926

Vernier JP, Fairlie TD, Murray JJ, Tupper A, Trepte C, Winker D, Pelon J, Garnier A, Jumelet J, Pavolonis M, Omar AH, Powell KA (2013) An advanced system to monitor the $3 d$ structure of diffuse volcanic ash clouds. J Appl Meteorol Climatol 52(9):2125-2138. doi:10.1175/JAMC-D-12-0279.1

Volentik ACM, Bonadonna C, Connor CB, Connor LJ, Rosi M (2010) Modeling tephra dispersal in absence of wind: insights from the climactic phase of the 2450 BP Plinian eruption of Pululagua volcano (Ecuador). J Volcanol Geotherm Res 193(1-2):117-136. doi:10.1016/j.jvolgeores.2010.03.011

Voronoi G (1907) Nouvelles applications des paramètres continus à la théorie des formes quadratiques. J reine angew Math 133:97-178

Walker GPL (1973) Explosive volcanic eruptions-a new classification scheme. Geol Rundsch 62:431-446. doi:10.1007/BF01840108

Watson DF, Phillip G (1987) Neighborhood-based interpolation. Geobyte 2(2):12-16

Wen S, Rose WI (1994) Retrieval of sizes and total masses of particles in volcanic clouds using AVHRR bands 4 and 5. J Geophys Res: Atmospheres 99(D3):5421-5431. doi:10.1029/93JD03340

Wilson L, Huang TC (1979) The influence of shape on the atmospheric settling velocity of volcanic ash particles. Earth Planet Sci Lett 44:311-324. doi:10.1016/0012-821X(79)90179-1

Woodhouse MJ, Hogg AJ, Phillips JC, Sparks RSJ (2013) Interaction between volcanic plumes and wind during the 2010 Eyjafjallajökull eruption, Iceland. J Geophys Res 118:92-109. doi:10.1029/2012JB009592 